\title{
Evolução da Ocupação e do Rendimento das Pessoas no Espaço Rural Brasileiro no Período de 2001 a 2009
}

\author{
Antonio Carlos Laurenti ${ }^{1}$, Tiago Pellini² e Tiago Santos Telles ${ }^{3}$
}

\begin{abstract}
Resumo: Na última década do século XX constatou-se uma crescente diversificação na composição ocupacional e um lento crescimento da população rural brasileira em idade ativa. O objetivo deste estudo é apresentar, para o período de 2001 a 2009, as principais tendências de ocupação e rendimento das pessoas residentes no meio rural brasileiro. A partir dos microdados da Pesquisa Nacional por Amostra de Domicílios (PNAD) e com base em um modelo de regressão log-linear, foram analisadas as variações na população, no rendimento, no rendimento médio e no índice de Gini. Constatou-se que, não obstante o declínio na PEA rural ocupada na agricultura mercantil, a população rural brasileira se manteve estável devido, principalmente, à expansão da PEA com ocupação não agrícola. A mudança no perfil do meio rural brasileiro foi mais evidente no âmbito do rendimento das pessoas. Tais tendências se associaram à diversificação da composição ocupacional, ao aumento do poder aquisitivo, à redução na desigualdade econômica e da informalidade na relação de emprego. A continuidade dessas tendências pode fazer com que, na área rural, a ocupação e renda das atividades agrícolas sejam superadas pelas oriundas de atividades não agrícolas. Portanto, há necessidade de readequação das iniciativas de desenvolvimento rural.
\end{abstract}

Palavras-chaves: PEA rural, ocupação agrícola, ocupação não agrícola, PNAD, índice de Gini.

Abstract: In the last decade of the 20th century it was observed an increasing diversification in the composition of the agricultural occupation and a slow increasing of Brazilian rural population in productive age. The aim of this study was to report the main tendencies on occupation and income of population in the rural space of Brazil in the 2001-2009 period. From the data of National Household Sample Survey (PNAD) and based in a log-linear regression model, an analysis on variation in population, income, average income and Gini index was made. It was identified that, despite the continuous

1. Instituto Agronômico do Paraná - Iapar. Londrina, Paraná, Brasil. E-mail: laurenti@iapar.br

2. Instituto Agronômico do Paraná - Iapar. Londrina, Paraná, Brasil. E-mail: tpellini@iapar.br

3. Instituto Agronômico do Paraná - Iapar. Londrina, Paraná, Brasil. E-mail: telles@iapar.br 
decline of the total economically active population (EAP) occupied in the mercantile agriculture, the Brazilian rural population remained stable, mainly due to the expansion of EAP with off-agricultural occupation. The change on the profile of Brazilian rural space was more evident in the population income. These tendencies are associated with the diversification of the occupational composition, the increase of the acquisitive power, the reduction of the access to income inequality and the decrease of informal employment in the rural space. The continuity of these trends may lead to, in the rural area, both occupation and income from agricultural activities are surpassed by those originated from off-agricultural activities. Therefore, the readjustment of the rural development initiatives, which are mainly focused in the agricultural activities, is necessary.

Key-words: Rural economically active population, agricultural occupation, off-agricultural occupation, National Household Sample Survey, Gini index.

http://dx.doi.org/10.1590/1234-56781806-9479005302008

\section{Introdução}

Na última década do século XX, constatou-se uma crescente diversificação na composição ocupacional e um lento crescimento da população rural brasileira com 10 anos ou mais de idade. Essas tendências resultaram, basicamente, na expansão do pessoal ocupado em atividade não agrícola e da população não economicamente ativa. Tal dinâmica, conforme Projeto Rurbano ${ }^{4}$, foi denominada de "novo rural", pois ensejou uma ampla e mais eclética abordagem do mundo rural brasileiro. No Brasil, dentre os estudos realizados para compreender essas mudanças, destacam-se os de Graziano da Silva (1996, 1997, 2001, 2002), Campanhola e Graziano da Silva (2000a, 2000b, 2000c, 2000d, 2004a, 2004b, 2004c), Schneider e Navarro (2000), Balsadi (2001), Graziano da Silva e Del Grossi (2001), Graziano da Silva et al. (2002), Hoffmann (2002) e Kageyama (2003, 2004).

4. O Projeto Rurbano, denominado "Caracterização do Novo Rural Brasileiro", teve início em 1997 com a finalidade de investigar as tendências do emprego agrícola das áreas rurais do território brasileiro a partir dos microdados da PNAD do IBGE, explorando basicamente os tipos de ocupações das pessoas residentes nas áreas rurais e as rendas das famílias agrícolas, pluriativas e não agrícolas residentes nas áreas rurais. Tal projeto foi organizado pelo Instituto de Economia da Unicamp, sob a coordenação do professor doutor José Graziano da Silva, no qual foi composta uma rede de pesquisa envolvendo 25 profissionais de diversas instituições de ciência e tecnologia, de 11 estados brasileiros.
Na década de 2000, outros estudos apresentaram uma atualização dos resultados sobre a evolução da ocupação e do rendimento das pessoas e famílias domiciliadas no meio rural. No âmbito nacional destacam-se, dentre outros, Del Grossi e Graziano da Silva (2006), Ferreira et al. (2006), Balsadi e Gomes (2007), Campolina et al. (2009) e Laurenti (2010). Por sua vez, em uma perspectiva regional, distinguem-se Balsadi (2005) e Balsadi e Borin (2006), para o estado de São Paulo; Cunha (2008), Basotti et al. (2009) e Laurenti (2010, 2013), para o Paraná; Balsadi (2008), para o Centro-Oeste; e Alves e Paulo (2012), para o Ceará. O ponto de convergência dessas investigações é a análise das mudanças no meio rural brasileiro utilizando os dados da Pesquisa Nacional por Amostra de Domicílios (PNAD), do Instituto Brasileiro de Geografia e Estatística (IBGE).

No período de 2001 a 2008, dentre as tendências constatadas pelo Projeto Rurbano, confirmaram-se as de diminuição do pessoal ocupado na agricultura mercantil ${ }^{5}$, de aumento da população rural ocupada em atividade comercial não agrícola e de expansão da população ocupada na produção para o próprio consumo. Ademais, do ponto de

5. Corresponde à PEA ocupada em atividades agrícolas, exceto o pessoal ocupado uma hora ou mais na semana, no trabalho principal ou secundário, em atividades de autoconsumo e o pessoal ocupado sem remuneração em dinheiro, produto ou serviço e com carga horária semanal de até 15 horas. Em outras palavras, corresponde, basicamente, quase à totalidade da PEA ocupada em atividades agrícolas para fins comerciais. 
vista socioeconômico, verificou-se que é no âmbito do rendimento das pessoas que melhor se denota a mudança do perfil da população rural brasileira. Além da composição ocupacional mais heterogênea, o espaço rural vem sendo demarcado pelo incremento do poder aquisitivo, pela redução da desigualdade no acesso ao rendimento e pelo "arrefecimento" da pobreza (LAURENTI, 2010).

Não obstante serem suficientes os resultados já obtidos para subsidiar a elaboração de uma nova e eclética agenda pública de melhoria e de desenvolvimento do meio rural brasileiro, entende-se que é útil um exame atualizado da continuidade das tendências e dos prognósticos, permitindo caracterizar de maneira mais compartimentalizada o atual perfil do meio rural brasileiro. Isto é particularmente importante pelo fato de que as recentes iniciativas de diversificação da pauta de produção, como maneira de se elevar a renda da agricultura e promover a preservação do meio ambiente, associadas à busca de novas fontes de energia oriunda da biomassa, tendem a se defrontar com uma competição mais acirrada no mercado de trabalho. Notadamente devido ao avanço das ocupações não agrícolas no conjunto da população com domicílio rural, que geralmente oferecem rendimentos superiores aos das ocupações agrícolas (NEY e HOFFMANN, 2008).

Nesse contexto, o objetivo desse estudo é verificar a continuidade das tendências de ocupação e rendimento da população economicamente ativa (PEA) rural, no Brasil, no período de 2001 a 2009.

Além desta introdução, esse trabalho contém outras três seções. A primeira delas é destinada à exposição das hipóteses, conceitos e procedimentos metodológicos que vêm sendo empregados na identificação das tendências em pauta, bem como os indicadores utilizados para a caracterização da evolução do rendimento das pessoas. Na segunda seção são apresentados os principais resultados do trabalho no que diz respeito à distribuição da população rural e à evolução do rendimento do trabalho principal, com o propósito de ilustrar a redução gradativa do predomínio da agricultura mercantil como atividade geradora de postos de ocupação para a população rural. Além disso, é apresentada a evolução da desigualdade da distribuição do rendimento e da população rural em situação de pobreza. Na terceira e conclusiva seção, com base nas principais constatações consolidadas sobre o novo rural brasileiro, são apresentadas as considerações finais, elencando algumas implicações associadas à readequação de iniciativas públicas para o desenvolvimento rural, realçando a importância de readequação de iniciativas públicas, particularmente quanto à inclusão de ações de cunho local na agenda de melhoria das condições de vida e ao desenvolvimento rural ${ }^{6}$.

\section{Hipóteses, conceitos e procedimentos metodológicos}

A presente averiguação está calcada na suposição de que, afora algumas diferenças de ordem local e no valor das taxas de variação anual, devem persistir as tendências observadas no espaço rural brasileiro, sinalizadas por Del Grossi e Graziano da Silva (2006), particularmente a de crescimento da população rural de 10 anos ou mais de idade - que vem sendo acompanhada da redução do predomínio quantitativo da PEA rural ocupada na agricultura. Isto, num contexto de reincidência do declínio da PEA rural ocupada na agricultura mercantil e de expansão da PEA rural ocupada em atividades comerciais não agrícolas, do aumento do número de pessoas não ocupadas e procurando emprego e do total de inativos.

Outra hipótese do estudo é verificar se as características do meio rural brasileiro são mais proeminentes no âmbito rendimentos do que no contexto demográfico, como constatado nos trabalhos sobre o "novo rural". Ademais, buscar-se-á verificar as suposições quanto à continuidade do aumento dos rendimentos e da diminuição na desigualdade do acesso à renda. Por fim, as tendências especificadas poderão não se repetir integralmente, em particular no que se refere à magnitude das taxas anuais de variação.

6. Conforme proposições de Campanhola e Graziano da Silva (2005), que enfatizaram a relevância da utilização de um elenco mais eclético de ações para o desenvolvimento local. 
Para examinar a continuidade da tendência de crescimento da PEA rural ocupada em atividade não agrícola no período de 2001 a 2009, será observado o sentido da variação expresso pelos coeficientes angulares de equação de regressão do tipo log-linear que relaciona a estimativa do tamanho da população ao correspondente ano de observação. A taxa de variação anual é expressa em percentagem, com a aceitabilidade das hipóteses aferidas pela aplicação do teste de $t$, considerando-se níveis de significância de $5 \%, 10 \%$ e $20 \%$.

Com relação à verificação da reincidência da dinâmica demográfica que ensejou a concepção do "novo rural", serão utilizados os mesmos conceitos e procedimentos metodológicos empregados por Laurenti e Del Grossi (2008), em investigação análoga realizada para o período de 2001 a 2006. Particular atenção recai sobre a PEA, estimada com base no conceito de trabalho vigente na PNAD até 1992, aqui designado de PEA restrita (PEAr). Grosso modo, a PEAr ocupada na agricultura corresponde ao pessoal ocupado na agricultura mercantil. Analogamente, a PEAr rural com ocupação fora da agricultura corresponde à PEA rural ocupada em atividade comercial não agrícola.

Nesta investigação, o conceito de área rural advém da delimitação dos perímetros urbanos estabelecido pelos legisladores municipais, que é mantida durante todo o período intercensitário. Além disso, a contagem da população considerada pelo IBGE para fins da PNAD e do censo demográfico não inclui na população rural o habitante de sede distrital ou de vila, que é legalmente considerado como morador urbano e, portanto, integrante da população urbana. A vigência do perímetro ao longo do período intercensitário faculta a comparabilidade interanual das PNAD.

O conjunto de dados é composto pelos microdados reponderados das PNAD de 2001 a 2007 e de 2008 e 2009. A estrita comparabilidade entre as estimativas obtidas a partir das PNAD depende do recálculo dos pesos utilizados para expansão da amostra, que são fornecidos pelo IBGE. Para o período de 2001 a 2007, a reponderação foi feita com base na projeção da população de 2008, considerando-se a atualização dos indicadores demográfi- cos (fecundidade, mortalidade e migrações), obtida por meio da contagem da população feita em 2007.

No exame das tendências relativas ao rendimento das pessoas, será considerada, inicialmente, a população de 10 anos ou mais de idade com declaração e com anotação do valor do rendimento, tendo-se como referência o montante do rendimento mensal de todas as fontes, cujas estimativas serão efetuadas para os respectivos subgrupos de pessoas definidos no contexto da composição ocupacional. Para a PEA ocupada será também descrita a evolução do rendimento tendo-se em consideração somente o rendimento do trabalho principal ou exclusivo. Os coeficientes angulares das equações de regressão das variações do rendimento total, da sua respectiva participação relativa do rendimento médio e do índice de Gini, indicarão o sentido e o grau de variação do poder aquisitivo e da desigualdade do acesso ao rendimento das pessoas domiciliadas na área rural. Para tanto, será utilizado o mesmo modelo de regressão aplicado na descrição das tendências de variação da população quanto à ocupação. Posteriormente, reaplica-se o referido modelo de regressão tendo em conta o rendimento familiar per capita, calculado conforme Equação 1, com a finalidade de se avaliar a evolução da distribuição do rendimento, segundo alguns estratos de salário mínimo (SM), com a finalidade de aferir a evolução da participação relativa de cada faixa de rendimento, especialmente daquela correspondente à população relativamente mais pobre. As faixas consideradas são: de mais de 0 até $1 / 4$ de SM, de mais de $1 / 4$ até $1 / 2 \mathrm{SM}$, de mais de $1 / 2$ até $1 \mathrm{SM}$, de mais de 1 até $2 \mathrm{SM}$, de mais de 2 até $3 \mathrm{SM}$, de mais de 3 até 5 SM e de mais de 5 SM até o maior valor presente na distribuição.

$$
\mathrm{RFPC}=\frac{\mathrm{TRF}}{\mathrm{n}}
$$

sendo: RFPC os valores do rendimento mensal familiar per capita; TRF o valor do total do rendimento mensal de todas as fontes da família extensa ( $v 4722$ no dicionário de variáveis da PNAD), levando-se em conta somente os valores maiores que zero; e $n$ o número de pessoas da família extensa (v4724 no dicionário de variáveis da PNAD). 
A definição de família extensa abrange os integrantes do núcleo familiar e respectivos parentes, acrescido das pessoas agregadas (coabitantes do domicílio que não são parentes da família e que não pagam hospedagem ou alimentação), conforme Graziano da Silva e Del Grossi (2001). A partir de 2003, tal especificação passou a ser referida como o conjunto de moradores da unidade domiciliar resultante da exclusão das pessoas relacionadas à família como pensionista, empregado doméstico e do parente de empregado doméstico. Nesta investigação, tais especificações foram consideradas como equivalentes, notadamente pelo fato de que o total de pessoas da família extensa corresponde à quase totalidade da população com 10 anos ou mais de idade.

O procedimento de cálculo das estimativas do índice de Gini segue a formulação de Hoffmann (2006, p. 340), apresentada na Equação 2.

$$
G=1-\frac{1}{n} \sum_{i=1}^{n}\left(\varphi_{i-1}+\varphi_{i}\right)
$$

sendo: G o índice de Gini.; $n$ o total das pessoas da família extensa; e $\varphi$ a proporção acumulada do rendimento das pessoas até a i-ésima família extensa.

\section{Resultados e discussão}

Nesta seção são apresentados os resultados sobre a variação da população rural brasileira, do rendimento do trabalho principal da população com moradia no meio rural, da desigualdade da distribuição do rendimento e da população rural em situação de pobreza.

São destacadas as tendências de evolução da participação relativa e da magnitude de vários segmentos populacionais e dos respectivos montantes do rendimento das pessoas com 10 anos ou mais de idade para a União, com ênfase na ausência do declínio numérico da população rural, na continuidade do crescimento do montante do rendimento da população rural com 10 anos ou mais de idade e na diminuição da importância relativa da agropecuária como fonte de postos de ocupação e rendimento das pessoas. Também são expos- tos os resultados relativos à população da "família extensa" com rendimento mensal familiar per capita, com a finalidade de se delinear a evolução: do poder aquisitivo (rendimento médio); da desigualdade econômica; do tamanho e do montante do rendimento da população brasileira em situação de pobreza e de extrema pobreza.

Além disso, é apresentada a distribuição da população rural quanto à posição na ocupação, com as principais variações na participação relativa e no tamanho da PEA rural ocupada, considerando, entre outras, as categorias: empregado, empregador e conta própria.

\subsection{Variação da população rural}

A participação relativa da população rural no total de pessoas residentes no Brasil foi reduzida de 16,1\% em 2001 para 14,7\% em 2009 (Tabelas 1 e 2). A ausência de crescimento absoluto da população rural e o crescimento da população urbana, no conjunto, explicam a queda da participação relativa da população rural. Também foi verificada uma queda na participação relativa da população com 10 ou mais anos de idade, a qual se situava próxima de 15,6\% em 2001, passando à 14,3\% em 2009 - ainda que a população rural de 10 anos ou mais de idade tenha experimentado um crescimento consistente, em termos absolutos, à taxa de $0,9 \%$ ao ano. Tal declínio confirma a ideia de que o despovoamento é um movimento que tende a se esgotar na dinâmica demográfica das áreas rurais de países industrializados, ou em vias de industrialização. Porém, de 2001 a 2009, o contínuo decréscimo da participação relativa da população rural e da população rural de 10 anos no território nacional, a uma taxa anual de, respectivamente, $1,1 \%$ e $0,9 \%$, não foi acompanhada do esvaziamento populacional do meio rural, em termos absolutos. A prova disto é que a população rural se manteve em torno de 27,7 milhões de pessoas no período, em decorrência do acréscimo de quase 1,4 milhão no grupo de pessoas com 10 anos ou mais de idade, que contrabalanceou a queda, em similar magnitude, no grupamento das crianças (Tabela 2). 


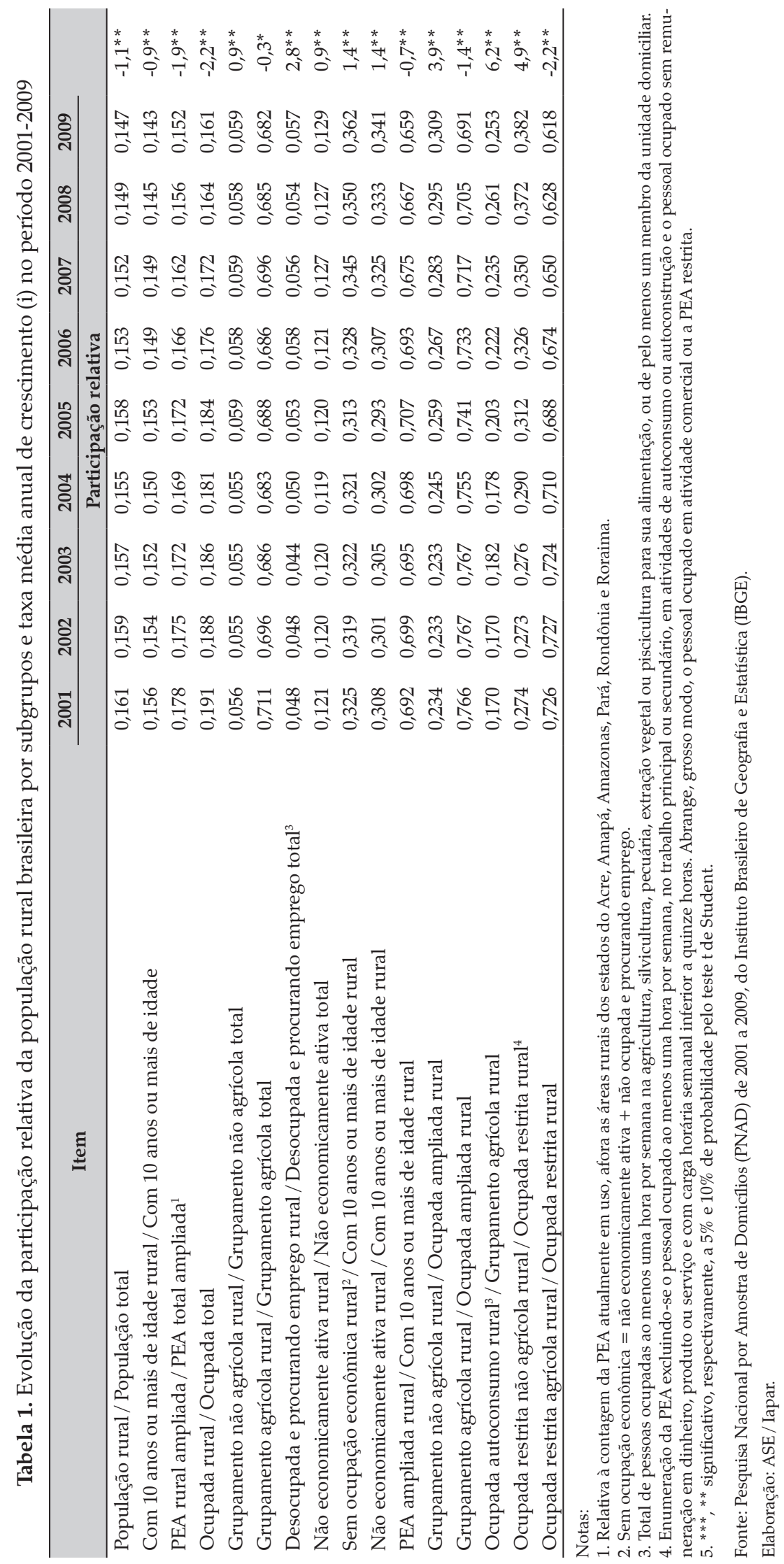


Tabela 2. Evolução da população brasileira por situação de domicílio, condição na ocupação e setor de atividade principal, e taxa média anual de crescimento (i) no período 2001-2009

\begin{tabular}{|c|c|c|c|c|c|c|c|c|c|c|}
\hline \multirow{2}{*}{ Item } & 2001 & 2002 & 2003 & 2004 & 2005 & 2006 & 2007 & 2008 & 2009 & $i^{6}$ \\
\hline & \multicolumn{9}{|c|}{ Milhares de pessoas } & $\%$ \\
\hline Total & 170.955 & 173.501 & 175.954 & 178.309 & 180.580 & 182.807 & 184.902 & 186.908 & 188.703 & $1,2^{* * *}$ \\
\hline Com 10 anos ou mais de idade & 138.962 & 141.819 & 144.568 & 146.918 & 149.829 & 152.811 & 155.455 & 158.210 & 160.438 & $1,8^{* * *}$ \\
\hline Economicamente ativa ampliada ${ }^{1}$ & 84.018 & 86.963 & 88.774 & 90.871 & 94.046 & 95.179 & 96.308 & 98.009 & 99.576 & $2,1 * * *$ \\
\hline Sem declaração $(a)$ & 17 & 12 & 18 & 12 & 11 & 0 & 0 & 0 & 0 & \\
\hline Ocupada $(b)$ & 76.163 & 79.008 & 80.147 & 82.674 & 85.180 & 87.091 & 88.385 & 90.935 & 91.208 & $2,3^{* * * *}$ \\
\hline Não agrícola & 60.459 & 62.655 & 63.497 & 66.118 & 68.274 & 70.760 & 72.772 & 75.630 & 76.370 & $3,1^{* * *}$ \\
\hline Agrícola & 15.704 & 16.353 & 16.650 & 16.555 & 16.906 & 16.331 & 15.614 & 15.305 & 14.838 & $-0,9^{*}$ \\
\hline Não ocupada² $(c)$ & 7.855 & 7.955 & 8.627 & 8.198 & 8.866 & 8.088 & 7.922 & 7.074 & 8.368 & $-0,5^{\mathrm{NS}}$ \\
\hline Não economicamente ativa & 54.927 & 54.856 & 55.793 & 56.047 & 55.783 & 57.632 & 59.147 & 60.201 & 60.862 & $1,4^{* * *}$ \\
\hline Urbana & 143.378 & 145.913 & 148.256 & 150.689 & 152.138 & 154.751 & 156.763 & 159.095 & 161.041 & $1,4^{* * *}$ \\
\hline Com 10 anos ou mais de idade & 117.350 & 120.035 & 122.578 & 124.894 & 126.974 & 130.072 & 132.325 & 135.321 & 137.467 & $2,0^{* * *}$ \\
\hline Economicamente ativa ampliada ${ }^{1}$ & 69.062 & 71.744 & 73.493 & 75.505 & 77.889 & 79.422 & 80.702 & 82.742 & 84.446 & $2,5^{* * *}$ \\
\hline Sem declaração $(a)$ & 17 & 11 & 14 & 11 & 9 & 0 & 0 & 0 & 0 & - \\
\hline Ocupada $(b)$ & 61.585 & 64.174 & 65.248 & 67.716 & 69.489 & 71.801 & 73.224 & 76.054 & 76.556 & $2,8^{* * *}$ \\
\hline Não agrícola & 57.049 & 59.202 & 60.021 & 62.459 & 64.217 & 66.678 & 68.477 & 71.236 & 71.839 & $3,1^{* * *}$ \\
\hline Agrícola & 4.535 & 4.972 & 5.227 & 5.256 & 5.272 & 5.123 & 4.748 & 4.818 & 4.717 & $-0,3^{\mathrm{NS}}$ \\
\hline Não ocupada² $(c)$ & 7.478 & 7.570 & 8.246 & 7.790 & 8.400 & 7.621 & 7.478 & 6.689 & 7.890 & $-0,6$ \\
\hline Não economicamente ativa & 48.271 & 48.290 & 49.085 & 49.388 & 49.086 & 50.651 & 51.624 & 52.578 & 53.021 & $1,3^{* * *}$ \\
\hline Rural & 27.577 & 27.588 & 27.698 & 27.620 & 28.442 & 28.055 & 28.139 & 27.813 & 27.662 & $0,1^{\mathrm{NS}}$ \\
\hline Com 10 anos ou mais de idade & 21.612 & 21.785 & 21.989 & 22.024 & 22.855 & 22.739 & 23.129 & 22.889 & 22.972 & $0,9^{* * *}$ \\
\hline Economicamente ativa ampliada ${ }^{1}$ & 14.956 & 15.219 & 15.281 & 15.366 & 16.158 & 15.758 & 15.606 & 15.267 & 15.130 & $0,2^{\mathrm{NS}}$ \\
\hline Sem declaração $(a)$ & 1 & 1 & 5 & 2 & 2 & 0 & 0 & 0 & 0 & - \\
\hline Ocupada $(b)$ & 14.579 & 14.834 & 14.899 & 14.958 & 15.691 & 15.290 & 15.161 & 14.882 & 14.652 & $0,1^{\mathrm{NS}}$ \\
\hline Não agrícola & 3.410 & 3.453 & 3.476 & 3.659 & 4.057 & 4.083 & 4.295 & 4.394 & 4.531 & $4,1^{* * *}$ \\
\hline Agrícola & 11.169 & 11.381 & 11.423 & 11.299 & 11.634 & 11.207 & 10.866 & 10.488 & 10.121 & $-1,2^{* * *}$ \\
\hline Não remunerada $(d)$ & 389 & 420 & 418 & 471 & 479 & 481 & 504 & 441 & 327 & $-0,2^{\mathrm{NS}}$ \\
\hline Não agrícola & 35 & 39 & 38 & 32 & 42 & 54 & 48 & 34 & 32 & $0,4^{\mathrm{NS}}$ \\
\hline Agrícola & 353 & 381 & 380 & 440 & 437 & 427 & 457 & 407 & 295 & $-0,3^{\mathrm{NS}}$ \\
\hline Próprio uso ou consumo $(e)$ & 1.909 & 1.949 & 2.089 & 2.019 & 2.377 & 2.505 & 2.570 & 2.746 & 2.575 & $4,9^{* * *}$ \\
\hline Autoconstrução & 11 & 11 & 16 & 6 & 12 & 20 & 16 & 10 & 13 & $2,7^{\mathrm{NS}}$ \\
\hline Autoconsumo ${ }^{4}$ & 1.898 & 1.938 & 2.073 & 2.013 & 2.365 & 2.485 & 2.555 & 2.736 & 2.561 & $4,9^{* * *}$ \\
\hline Economicamente ativa restrita ${ }^{5}(f)$ & 12.658 & 12.850 & 12.774 & 12.875 & 13.301 & 12.773 & 12.531 & 12.080 & 12.228 & $-0,6^{*}$ \\
\hline Ocupada restrita $(g)$ & 12.281 & 12.466 & 12.392 & 12.467 & 12.835 & 12.305 & 12.086 & 11.694 & 11.750 & $-0,7^{* *}$ \\
\hline Não agrícola & 3.363 & 3.403 & 3.422 & 3.621 & 4.003 & 4.009 & 4.232 & 4.349 & 4.485 & $4,1^{* * *}$ \\
\hline Agrícola & 8.918 & 9.062 & 8.970 & 8.846 & 8.832 & 8.295 & 7.855 & 7.345 & 7.265 & $-2,9 * * *$ \\
\hline Não ocupada $(c)$ & 377 & 385 & 382 & 408 & 467 & 468 & 445 & 385 & 478 & $2,4^{* *}$ \\
\hline Não economicamente ativa & 6.656 & 6.566 & 6.708 & 6.658 & 6.697 & 6.981 & 7.523 & 7.622 & 7.842 & $2,3^{* * *}$ \\
\hline
\end{tabular}

Notas:

1. Relativo à contagem da PEA atualmente em uso e corresponde à $a+b+c$. Afora as áreas rurais dos estados do Acre, Amapá, Amazonas, Pará, Rondônia e Roraima.

2. Total de pessoas desocupadas que procuraram emprego no período de referência.

3. Total de pessoas ocupadas ao menos uma hora por semana na construção de estrada privativa, poço ou outra benfeitoria (exceto reforma) para seu uso, ou para uso de pelo menos um membro da unidade domiciliar.

4. Total de pessoas ocupadas ao menos uma hora por semana na agricultura, silvicultura, pecuária, extração vegetal ou piscicultura para sua alimentação, ou de pelo menos um membro da unidade domiciliar.

5. Enumeração da PEA excluindo-se o pessoal ocupado ao menos uma hora por semana, no trabalho principal ou secundário, em atividades de autoconsumo ou autoconstrução e o pessoal ocupado sem remuneração em dinheiro, produto ou serviço e com carga horária semanal inferior a 15 horas. Abrange, grosso modo, o pessoal ocupado em atividade comercial ou a PEA restrita. Na população rural, a PEA restrita $(f)$ equivale a $g+c$, pelo que a PEA rural ampliada equivale a $a+d+e+f$, ou, mais apropriadamente, a $a+d+e+g+c$.

$6^{* * *}, * *, *$ significativo, respectivamente, a $5 \%, 10 \%$ e $20 \%$ de probabilidade pelo teste $t$ de Student; ${ }^{\text {Ns }}$ não significativo a $20 \%$ de probabilidade pelo teste $t$ de Student.

Fonte: Pesquisa Nacional por Amostra de Domicílios (PNAD) de 2001 a 2009, do Instituto Brasileiro de Geografia e Estatística (IBGE).

Elaboração: ASE / Iapar. 
A relativa estabilidade do tamanho da população rural, bem como o incremento da população com 10 anos ou mais de idade suscita inferir que as forças que promovem o progresso técnico na agricultura, e o consequente declínio quantitativo da população rural, não estiveram inertes no período em foco. Isto pelo fato do total da PEA rural ocupada ter se mantido estável, em torno de 15 milhões de pessoas no período averiguado. Assim, é plausível ter em conta que a intensificação do predomínio relativo da população urbana já não implica que a área rural venha alojar no futuro apenas um resquício da atual população rural. Essa constatação também é válida para outros subgrupos da população, tal como o da população não economicamente ativa, cujo crescimento consecutivo da fração rural, em termos absolutos, representou um pequeno acréscimo na sua participação relativa $(0,9 \%)$, finalizando o período com uma população em torno de 7,8 milhões de pessoas. No mesmo sentido, houve estabilidade no total da PEA rural, em torno de 15,2 milhões de pessoas no período em foco, embora sua participação relativa no total da PEA tenha decrescido à taxa anual de 1,9\% ao ano, de 2001 a 2009.

De modo similar, também se denota uma redução, à taxa de 2,2\% ao ano, da participação relativa da porção rural do subgrupo das pessoas ocupadas no total da PEA ocupada, ainda que em termos absolutos a parte rural desse subgrupo também tenha se mantido estável no período em foco. A estabilidade da PEA rural ocupada, em torno de 15 milhões de pessoas, foi resultado, em primeiro lugar, da diminuição da PEA rural ocupada na agricultura, principalmente em virtude do persistente declínio absoluto do pessoal ocupado na agricultura mercantil (ou da PEA agrícola, no conceito que vigorou na PNAD até 1992), cuja população decresceu à taxa de 2,9\% ao ano no período de 2001 a 2009. Essa dinâmica pode ser associada, entre outras razões, ao emprego de um conjunto de novas forças produtivas, iniciado desde meados dos anos 1960, que vêm reduzindo o requerimento de força de trabalho humana no processo produtivo da agropecuária.
Em segundo lugar, em função do aumento, em ritmo acelerado $(4,9 \%)$, do total de pessoas ocupadas exclusivamente na agricultura de autoconsumo. Esta expressiva taxa de crescimento da população dedicada unicamente à produção de autoconsumo elevou de $17,0 \%$ para $25,3 \%$ a participação desse subgrupo no total de pessoas com ocupação na agricultura e com domicílio rural.

Além dos fatores indicados, e não obstante a continuidade do uso de insumos modernos e da motomecanização na agricultura, tem-se que o principal movimento demográfico que se contrapõe ao gradativo despovoamento das áreas rurais do País é a expansão relativa (a uma taxa anual de $4,9 \%$, Tabela 1) e absoluta da população com ocupação não agrícola e com domicílio rural (4,1\% ao ano, Tabela 2), no período de 2001 a 2009. Este último em função da expansão do agrupamento das pessoas ocupadas em empreendimento comercial não agrícola, que também cresceu com taxa de $4,1 \%$ ao ano. Considerando o conceito de PEA que vigorava até 1992, a população rural ocupada em empreendimento comercial não agrícola perfazia, em 2009, quase 40\% da PEAr rural ocupada, ou da PEA restrita rural ocupada (Tabela 2). Assim, observa-se a persistência ou aumento das taxas anuais de variação dos diferentes subgrupos populacionais componentes da PEA rural (conceito hoje em uso), o que permite corroborar os resultados do "novo rural" no que tange à inevitabilidade do vazio populacional no meio rural. Notadamente, pela nova composição ocupacional da população residente no meio rural, demarcada pela crescente parcela da população com ocupação não agrícola e do pessoal ocupado na produção de autoconsumo, assume relevância o reconhecimento da necessidade de uma abordagem renovada e mais eclética das iniciativas de cunho produtivo direcionadas ao desenvolvimento rural.

Nesta abordagem, o elenco de ações dirigidas ao meio rural não deve se limitar às atividades produtivas agrícolas e/ou não agrícolas, em função do crescimento absoluto no total de pessoas domiciliadas no meio rural e não economicamente ativa (2,3\% ao ano, Tabela 2$)$, que perfez uma população de 7,8 milhões de pessoas em 
2009. Mesmo porque, no âmbito da população rural, somente decresceu, em termos absolutos, o subgrupo do pessoal ocupado na agricultura mercantil, sendo que nos demais subgrupos houve aumento. Assim, ganha aceitabilidade a hipótese de que há crescente participação relativa da função de moradia do meio rural, dadas as taxas anuais de crescimento de $1,4 \%$ da proporção entre a população não economicamente ativa rural sobre a população rural com 10 anos ou mais de idade, e de $1,4 \%$ na proporção da população rural sem ocupação econômica sobre a população rural com 10 anos ou mais de idade (Tabela 1). Os resultados obtidos favorecem a aceitação das hipóteses de crescimento da população rural de 10 anos ou mais de idade e da PEA rural com ocupação comercial não agrícola. Indicaram, também, o aumento no total de pessoas ocupadas com atividade não agrícola, ocupadas na produção para o próprio consumo e inativas no espaço rural. O incremento do conjunto desses subgrupos mais que compensou a diminuição da PEA rural ocupada na agricultura mercantil. O acelerado crescimento do subgrupo das pessoas ocupadas no autoconsumo não foi, porém, suficiente para evitar a redução do tamanho da população ocupada na agricultura. Ou seja, os resultados estão em consonância com aqueles obtidos pelo "novo rural", indicando que essas tendências não se limitam a uma peculiaridade dos anos 1990 (DEL GROSSI e GRAZIANO DA SILVA, 2006).

Além disso, houve uma redução relativa da função de local de trabalho que o meio rural exerce para a maioria da população rural, pois a participação relativa do subgrupo sem ocupação econômica foi crescente no período de 2001 a 2009. Tal avaliação é extensiva ao subgrupo das pessoas inativas. Porém, a validade dessa formulação se baseou no conceito antigo de PEA, ou seja, na PEA restrita ${ }^{7}$. Estimando-se o tamanho da popu-

7. Nesse conceito, a população não economicamente ativa também é integrada pelas pessoas com ocupação no autoconsumo, autoconstrução e dos trabalhadores não remunerados (com pelo menos até uma hora de jornada diária), a qual, junto ao pessoal não ocupado, perfazia cerca de $42,0 \%$ da população rural com 10 anos ou mais de idade em 1997 (LAURENTI e DEL GROSSI, 2000, p. 20). lação das pessoas não economicamente ativas para o ano de 2009 com base neste conceito, verifica-se que $46,8 \%$ do total de pessoas com 10 anos ou mais de idade não tinham vínculo ocupacional na área rural. Ou seja, isto indica que houve uma redução relativa do meio rural como espaço de trabalho para os habitantes dessa circunscrição geográfica, dado que a fração da população rural que trabalha na zona urbana é majoritária. Nesse caso, foi determinante o acelerado crescimento do total das pessoas ocupadas na produção de autoconsumo - que, no conceito corrente, pertence à PEA.

Em síntese, no que tange à variação da população rural, pode-se dizer que a população rural brasileira se manteve estável em termos de tamanho no período de 2001 a 2009 e vem mostrando, há mais de uma década, diversificação no perfil ocupacional e continuidade de crescimento absoluto da população rural de 10 anos ou mais de idade. Essa expansão da população rural em idade ativa vem ocorrendo num contexto de persistência do declínio absoluto do pessoal ocupado na agricultura mercantil. $O$ crescimento da população rural com 10 anos ou mais de idade e a diferenciação ocupacional da PEA decorreram, basicamente, da expansão do contingente de pessoas com ocupação em empreendimento comercial não agrícola. Isso indica a ocorrência de uma gradativa redução do predomínio da agricultura na dinâmica ocupacional dos habitantes da zona rural, notadamente no âmbito do empreendimento comercial. Quanto à ocupação como um todo, denota-se que o acelerado crescimento da população ocupada na produção de autoconsumo motiva a sua inclusão como um importante segmento das atividades produtivas rurais que, em conformidade com o atual conceito de trabalho, seria a circunscrição aparentemente mais apropriada para alojar esse tipo de atividade.

\subsection{Variação do rendimento das pessoas}

Considerando as informações das Tabelas 3 e 4, percebe-se que, de modo geral, a importância relativa em termos de rendimento da população 
rural com 10 anos ou mais de idade é, comparativamente, menor do que a sua participação em termos populacionais. A importância relativa da fração rural no rendimento total da população residente e com 10 anos ou mais de idade no período de 2001 a 2009 foi, em média, de 7,3\%, ou seja, cerca de metade da participação relativa da porção rural no todo da população com 10 anos ou mais de idade residente no Brasil, que se situou em torno de 16,1\% (Tabela 1). Todavia, no período em pauta, o total do rendimento dos moradores das áreas rurais cresceu, em termos absolutos, em ritmo superior (6,0\% ao ano) àquele das pessoas domiciliadas no meio urbano (4,5\% ao ano). Isto fez com que a participação relativa do rendimento dos habitantes do meio rural na renda total da população residente do País aumentasse em torno de $1,3 \%$ ao ano.

Similarmente, no contexto da PEA e da PEA ocupada, a participação relativa de $7,4 \%$ da fração rural no total do rendimento (Tabela 3) também correspondeu, aproximadamente, à metade daquela observada no âmbito demográfico (Tabela 1). Embora decrescente no período considerado, a participação relativa da PEA agrícola perfez 68,2\% em 2009, no âmbito ocupacional, enquanto que no plano do rendimento tal participação foi estimada em $56,1 \%$ para o mesmo ano. Isto num contexto em que o total do rendimento do pessoal ocupado na agropecuária cresceu, em termos absolutos, à taxa anual de 3,5\%, inclusive com taxas similares de crescimento nas áreas rural e urbana, fazendo com que a crescente participação relativa do segmento urbano, portanto, passasse a apropriar, ao final do período em foco, $44,9 \%$ do total do rendimento das pessoas associadas à atividade agrícola. $\mathrm{O}$ crescimento do rendimento das pessoas com ocupação na agricultura também incidiu com diferentes ritmos de expansão sobre a agricultura mercantil e a produção para o próprio consumo. Os rendimentos dos subgrupos rurais também aumentaram em termos absolutos em ritmo mais acelerado do que os seus respectivos subgrupos urbanos (Tabela 4). Dentre as pessoas com moradia no meio rural, o rendimento do subgrupo com produção para autoconsumo cresceu à taxa média de 13,0\% ao ano (Tabela 4).

A expansão do rendimento das pessoas domiciliadas no meio rural com 10 anos ou mais de idade ocorreu em ritmo mais acelerado do que a expansão da população rural dessa mesma faixa etária. Esta constatação também se verifica com relação à PEA, ainda que nesse subgrupo populacional a participação da fração rural tenha sido decrescente no âmbito demográfico e crescente no contexto do rendimento. Essa menor importância relativa da fração rural no âmbito do rendimento se repetiu no contexto da PEA rural ocupada, pois o rendimento das pessoas com ocupação não agrícola cresceu à taxa de 2,6\% ao ano, ao passo que o rendimento daquelas ocupadas na agricultura decresceu ao ritmo de 1,6\% ao ano. Em 2009, a participação relativa do total do rendimento das pessoas com ocupação não agrícola foi de $42,7 \%$, enquanto que no plano populacional a participação das pessoas ocupadas na agricultura no conjunto da PEA ocupada, embora decrescente a uma taxa de 1,9\% ao ano, foi de 30,9\% (Tabela 1). Tais variações também se deram, de modo mais acentuado, na PEA restrita rural ocupada, em que o rendimento do segmento não agrícola cresceu à taxa anual de $8 \%$ (Tabela 4), fazendo com que esse subgrupo passasse a apropriar $46,3 \%$ do rendimento total da população rural ocupada em atividade comercial, ao final do período em pauta. Tal fato indica que a conformação do atual perfil do meio rural vem se consolidando de maneira relativamente mais célere no âmbito do rendimento das atividades comerciais, ou da população rural com rendimento. Isto num contexto no qual se expandiu, em termos absolutos, tanto a magnitude do rendimento das pessoas ocupadas na agricultura, quanto o montante do rendimento das pessoas com ocupação não agrícola. 


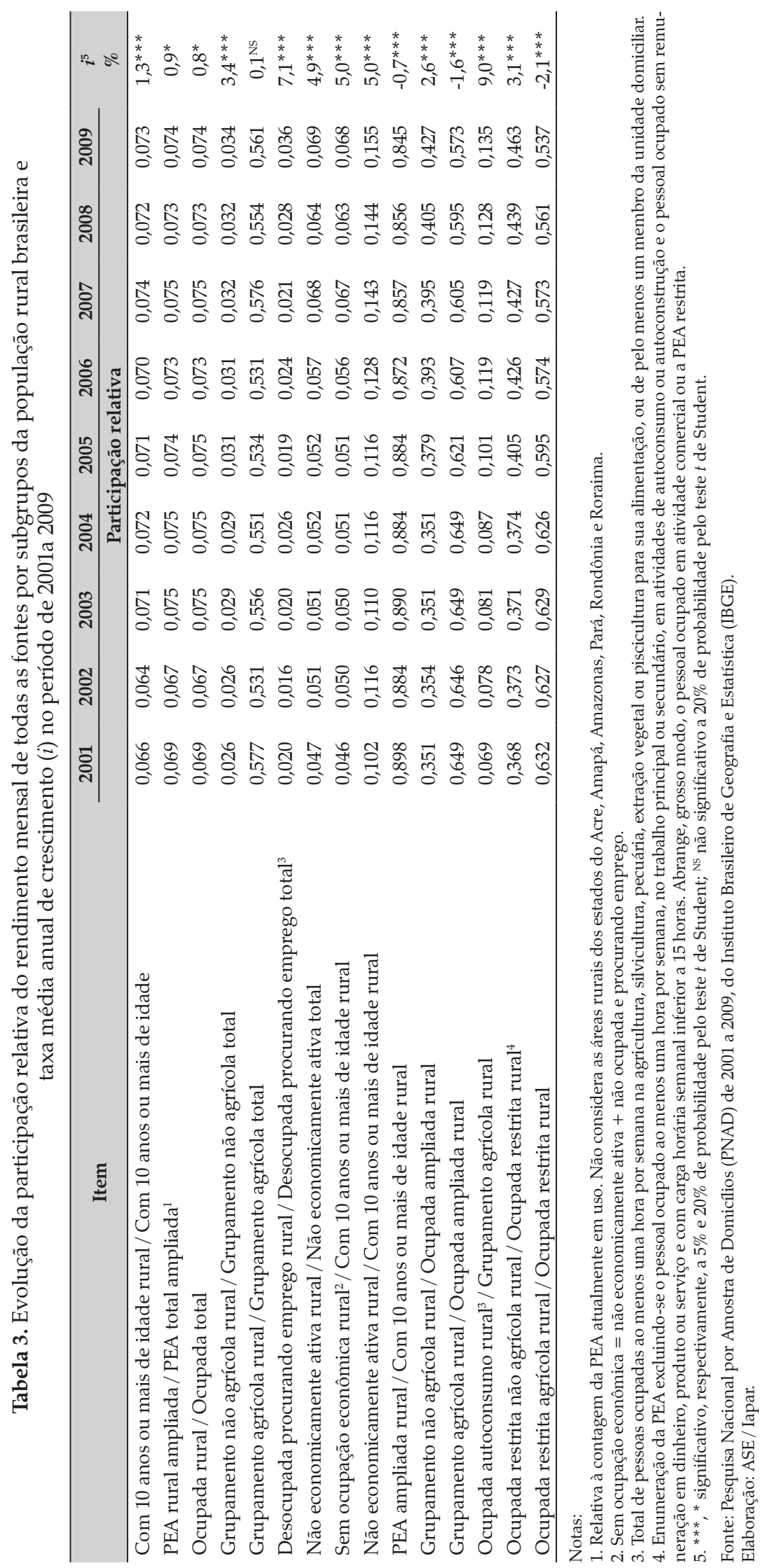


Tabela 4. Evolução do rendimento mensal de todas as fontes da população brasileira com 10 anos ou mais de idade e com rendimento, por situação de domicílio, condição na ocupação e setor de atividade principal, e taxa média anual de crescimento (i) no período 2001-2009

\begin{tabular}{|c|c|c|c|c|c|c|c|c|c|c|}
\hline \multirow{2}{*}{ Item } & 2001 & 2002 & 2003 & 2004 & 2005 & 2006 & 2007 & 2008 & 2009 & $\mathbf{i}^{6}$ \\
\hline & \multicolumn{9}{|c|}{ Em milhões de $\mathbf{R} \$^{7}$} & $\%$ \\
\hline Total & 86.967 & 88.728 & 84.070 & 87.714 & 95.046 & 104.687 & 108.335 & 115.052 & 118.612 & $4,6^{* * *}$ \\
\hline Economicamente ativa ampliada ${ }^{1}$ & 74.586 & 75.729 & 71.188 & 73.806 & 80.063 & 88.272 & 91.439 & 96.459 & 99.196 & $4,3 * * *$ \\
\hline Ocupada $(a)$ & 74.085 & 75.213 & 70.690 & 73.363 & 79.522 & 87.705 & 90.929 & 95.990 & 98.704 & $4,4^{* * *}$ \\
\hline Não agrícola $(c)$ & 68.306 & 69.085 & 64.473 & 66.842 & 72.600 & 80.368 & 83.727 & 88.430 & 91.238 & $4,4^{* * *}$ \\
\hline Agrícola $(d)$ & 5.779 & 6.128 & 6.217 & 6.521 & 6.922 & 7.337 & 7.202 & 7.560 & 7.466 & $3,5^{* * *}$ \\
\hline Não ocupada² $(b)$ & 501 & 516 & 498 & 443 & 542 & 567 & 509 & 469 & 493 & $-0,1^{\mathrm{NS}}$ \\
\hline Não economicamente ativa & 12.380 & 12.999 & 12.882 & 13.908 & 14.983 & 16.415 & 16.896 & 18.593 & 19.415 & $6,2 * * *$ \\
\hline Urbana & 81.231 & 83.023 & 78.076 & 81.437 & 88.300 & 97.315 & 100.313 & 106.820 & 109.943 & $4,5^{* * *}$ \\
\hline Economicamente ativa ampliada ${ }^{1}$ & 69.434 & 70.685 & 65.853 & 68.256 & 74.099 & 81.841 & 84.567 & 89.409 & 91.867 & $4,3^{* * *}$ \\
\hline Ocupada $(a)$ & 68.943 & 70.177 & 65.365 & 67.824 & 73.567 & 81.288 & 84.069 & 88.953 & 91.393 & $4,3 * * *$ \\
\hline Não agrícola $(c)$ & 66.500 & 67.305 & 62.603 & 64.896 & 70.345 & 77.843 & 81.015 & 85.580 & 88.119 & $4,3^{* * *}$ \\
\hline Agrícola $(d)$ & 2.442 & 2.873 & 2.763 & 2.928 & 3.222 & 3.444 & 3.054 & 3.374 & 3.274 & $3,4^{* * *}$ \\
\hline Não ocupada² $(b)$ & 491 & 508 & 488 & 432 & 532 & 553 & 499 & 456 & 475 & $-0,3^{\mathrm{NS}}$ \\
\hline Não economicamente ativa & 11.797 & 12.338 & 12.222 & 13.181 & 14.201 & 15.473 & 15.746 & 17.411 & 18.075 & $5,8^{* * *}$ \\
\hline Rural & 5.736 & 5.705 & 5.994 & 6.277 & 6.746 & 7.372 & 8.022 & 8.231 & 8.669 & $6,0^{* * *}$ \\
\hline Economicamente ativa ampliada ${ }^{1}$ & 5.153 & 5.044 & 5.334 & 5.550 & 5.964 & 6.431 & 6.871 & 7.050 & 7.329 & $5,2^{* * *}$ \\
\hline Ocupada $(a)$ & 5.143 & 5.036 & 5.324 & 5.539 & 5.954 & 6.417 & 6.861 & 7.037 & 7.311 & $5,2 * * *$ \\
\hline Não agrícola $(c)$ & 1.806 & 1.781 & 1.870 & 1.946 & 2.255 & 2.525 & 2.713 & 2.851 & 3.119 & $8,0^{* * *}$ \\
\hline Não remunerada $(e)$ & 6 & 1 & 1 & 1 & 1 & 1 & 5 & 10 & 6 & $19,1^{\mathrm{NS}}$ \\
\hline Autoconstrução ${ }^{3}(f)$ & 1 & 2 & 4 & 1 & 1 & 2 & 1 & 1 & 5 & $3,1^{\mathrm{NS}}$ \\
\hline Ocupada restrita ${ }^{4}(g)$ & 1.799 & 1.777 & 1.865 & 1.945 & 2.253 & 2.522 & 2.707 & 2.840 & 3.108 & $8,0^{* * *}$ \\
\hline Agrícola (d) & 3.337 & 3.255 & 3.454 & 3.593 & 3.700 & 3.892 & 4.148 & 4.186 & 4.192 & $3,6^{* * *}$ \\
\hline Não remunerada $(h)$ & 11 & 13 & 15 & 18 & 18 & 27 & 28 & 28 & 20 & $11,6^{* * *}$ \\
\hline Autoconsumo $^{5}(i)$ & 231 & 254 & 281 & 314 & 372 & 462 & 492 & 534 & 565 & $13,0^{* * *}$ \\
\hline Ocupada restrita $^{4}(j)$ & 3.094 & 2.989 & 3.158 & 3.261 & 3.309 & 3.404 & 3.627 & 3.624 & 3.607 & $2,5^{* * *}$ \\
\hline Não ocupada ${ }^{2}(b)$ & 10 & 8 & 10 & 11 & 10 & 14 & 10 & 13 & 18 & $7,0^{* * *}$ \\
\hline Não economicamente ativa & 583 & 661 & 660 & 727 & 782 & 941 & 1.151 & 1.181 & 1.340 & $11,3^{* * *}$ \\
\hline
\end{tabular}

Notas:

${ }^{1}$ Relativo à contagem da PEA atualmente em uso e corresponde a $a+b$. Não considera as áreas rurais dos estados do Acre, Amapá, Amazonas, Pará, Rondônia e Roraima

${ }^{2}$ Total de pessoas desocupadas que procuraram emprego no período de referência.

${ }^{3}$ Total de pessoas ocupadas ao menos uma hora por semana na construção de estrada privativa, poço ou outra benfeitoria (exceto reforma) para seu uso, ou para uso de pelo menos um membro da unidade domiciliar.

${ }^{4}$ Enumeração da PEA excluindo-se o pessoal ocupado ao menos uma hora por semana, no trabalho principal ou secundário, em atividades de autoconsumo ou autoconstrução e o pessoal ocupado sem remuneração em dinheiro, produto ou serviço e com carga horária semanal inferior a 15 horas. Abrange, grosso modo, o pessoal ocupado em atividade comercial ou a PEA restrita. Na população rural a PEA restrita equivale a $b+g+j$, pelo que a PEA rural ampliada equivale $\mathrm{a} b+c+d$ ou, mais apropriadamente, $\mathrm{a} b+e+f+g+h+i+j$.

${ }^{5}$ Total de pessoas ocupadas ao menos uma hora por semana na agricultura, silvicultura, pecuária, extração vegetal ou piscicultura para sua alimentação, ou de pelo menos um membro da unidade domiciliar.

${ }_{6 * * *}$ significativo a 5 de probabilidade pelo teste $t$ de Student; ${ }^{N S}$ não significativo a $20 \%$ de probabilidade pelo teste $t$ de Student.

${ }^{7}$ Valores atualizados com base no INPC de setembro de 2009.

Fonte: Pesquisa Nacional por Amostra de Domicílios (PNAD) de 2001 a 2009, do Instituto Brasileiro de Geografia e Estatística (IBGE).

Elaboração: ASE / Iapar. 
No âmbito do rendimento das pessoas não economicamente ativas, denota-se que a participação da população rural no total foi crescente, tendo atingido 6,9\% em 2009 (Tabela 3). Todavia, a população rural não economicamente ativa, cerca de 7,8 milhões de pessoas em 2009 (Tabela 2) - aproximadamente $28,4 \%$ do total da população domiciliada no meio rural -, contribuiu com uma pequena parcela no total dos rendimentos da população rural, cerca de 15,5\% (Tabela 4). Dado o elevado número de pessoas não economicamente ativas e sem rendimento, há necessidade de um elenco eclético de iniciativas de melhoria das condições de vida da população rural, as quais não devem se limitar às ações de cunho produtivo, stricto sensu.

Em síntese, os resultados apontam que o atual perfil do espaço rural brasileiro tem sido caracterizado, com mais acerto, no âmbito dos rendimentos das pessoas, comparativamente a sua expressão no contexto da composição ocupacional da população residente nas áreas rurais.

\subsection{Variação do rendimento médio, da desigualdade na distribuição do rendimento e da população rural em situação de pobreza no território brasileiro}

No conjunto das pessoas com rendimento, verifica-se que, tanto na totalidade da população quanto nos segmentos urbano e rural, o valor das estimativas do rendimento médio foi decrescente no anos iniciais e crescente no período de 2001 a 2009 (Tabela 5). Indica, portanto, tendência de crescimento do poder aquisitivo da população, o que foi relativamente mais consistente na população rural.

O ritmo de aumento do rendimento médio dos residentes no meio rural e com ocupação não agrícola, ao longo do período de 2001 a 2009, foi levemente superior àquele da PEA ocupada na agricultura, sendo que, supostamente, essa maior importância relativa seria ainda mais acentuada na ausência do declínio numérico do pessoal ocu- pado na agricultura. $\mathrm{O}$ aumento do rendimento médio, da PEA rural remunerada, nesse período, foi devido ao aumento do rendimento do pessoal ocupado na agricultura (Tabela 5), à estagnação da participação relativa desse subgrupo populacional no conjunto da PEA rural ocupada e ao crescimento no total do rendimento das pessoas com ocupação não agrícola, que ocorreu em ritmo superior ao de expansão no total de pessoas desse respectivo subgrupo populacional. Isto fez com que o rendimento médio desse grupamento fosse sempre superior ao rendimento médio do pessoal ocupado na agricultura. Tal situação se mostrou mais nítida no âmbito da PEA restrita, particularmente em função de que o rendimento da PEA ocupada na agricultura mercantil cresceu em termos absolutos (Tabela 5), enquanto se reduziu a quantidade de pessoas desse subgrupo populacional. Isto é, o acréscimo do rendimento médio da PEA ocupada na agricultura mercantil adveio tanto do aumento no total do rendimento como da diminuição da população com ocupação nesse setor de atividade.

Assim, a investigação da recente dinâmica do rendimento médio dos residentes das áreas rurais do País, de 2001 a 2009, permitiu constatar uma tendência de aumento do rendimento per capita no espaço rural brasileiro. Isto sugere que houve um aumento do poder de compra das pessoas, ao menos para a população rural com declaração de rendimento. Tal fenômeno ocorreu, sobretudo, em função da expansão da população e do rendimento do subgrupo com ocupação não agrícola, uma vez que o aumento do rendimento médio da PEA ocupada na agricultura foi concomitante ao contínuo declínio da PEA rural ocupada em atividade agrícola mercantil.

Além disso, observou-se uma melhoria na distribuição da renda na população rural, conforme tendência de redução do índice de Gini (Tabela 6), com destaque ao fato de que essa desigualdade tem se mostrado sistematicamente menor na área rural. 
Tabela 5. Evolução do rendimento médio mensal de todas as fontes da população brasileira com 10 anos ou mais de idade e com rendimento, por situação de domicílio, condição na ocupação e setor de atividade principal, e taxa média anual de crescimento (i) no período de 2001 a 2009

\begin{tabular}{|c|c|c|c|c|c|c|c|c|c|c|}
\hline \multirow{2}{*}{ Item } & 2001 & 2002 & 2003 & 2004 & 2005 & 2006 & 2007 & 2008 & 2009 & \multirow{2}{*}{$\begin{array}{l}i^{6} \\
\% \\
\end{array}$} \\
\hline & \multicolumn{9}{|c|}{$\mathbf{R} \$^{7}$} & \\
\hline Total & 1.034 & 1.001 & 917 & 919 & 966 & 1.027 & 1.053 & 1.074 & 1.094 & $1,4^{*}$ \\
\hline Economicamente ativa ampliada ${ }^{1}$ & 1.080 & 1.048 & 965 & 962 & 1.010 & 1.081 & 1.111 & 1.131 & 1.153 & $1,5^{* *}$ \\
\hline Ocupada $(a)$ & 1.087 & 1.056 & 974 & 972 & 1.021 & 1.093 & 1.121 & 1.141 & 1.167 & $1,5^{* *}$ \\
\hline Não agrícola $(c)$ & 1.182 & 1.150 & 1.059 & 1.052 & 1.103 & 1.181 & 1.200 & 1.218 & 1.246 & $1,3^{*}$ \\
\hline Agrícola $(d)$ & 557 & 550 & 531 & 546 & 572 & 603 & 636 & 655 & 657 & $2,8^{* * *}$ \\
\hline Não ocupada ${ }^{2}(b)$ & 553 & 498 & 422 & 351 & 404 & 404 & 427 & 406 & 350 & $-3,7^{* * *}$ \\
\hline Não economicamente ativa & 824 & 791 & 718 & 742 & 783 & 807 & 819 & 852 & 867 & $1,3^{*}$ \\
\hline Urbana & 1.124 & 1.090 & 993 & 992 & 1.045 & 1.109 & 1.129 & 1.152 & 1.172 & $1,2^{*}$ \\
\hline Economicamente ativa ampliada ${ }^{1}$ & 1.178 & 1.145 & 1.048 & 1.041 & 1.098 & 1.173 & 1.195 & 1.215 & 1.237 & $1,3^{*}$ \\
\hline Ocupada $(a)$ & 1.187 & 1.156 & 1.059 & 1.054 & 1.111 & 1.187 & 1.208 & 1.227 & 1.253 & $1,3^{*}$ \\
\hline Não agrícola $(c)$ & 1.218 & 1.185 & 1.087 & 1.081 & 1.135 & 1.212 & 1.233 & 1.251 & 1.279 & $1,2^{*}$ \\
\hline Agrícola $(d)$ & 700 & 735 & 669 & 683 & 761 & 814 & 776 & 831 & 810 & $2,4^{* * *}$ \\
\hline Não ocupada² $(b)$ & 560 & 510 & 430 & 358 & 414 & 415 & 440 & 418 & 361 & $-3,5^{* *}$ \\
\hline Não economicamente ativa & 885 & 852 & 773 & 795 & 836 & 861 & 871 & 908 & 925 & $1,2^{*}$ \\
\hline Rural & 485 & 457 & 460 & 470 & 485 & 518 & 570 & 571 & 593 & $3,4^{* * *}$ \\
\hline Economicamente ativa ampliada ${ }^{1}$ & 509 & 479 & 489 & 496 & 507 & 543 & 597 & 600 & 623 & $3,3^{* * *}$ \\
\hline Ocupada $(a)$ & 509 & 480 & 490 & 497 & 508 & 545 & 599 & 602 & 626 & $3,4^{* * *}$ \\
\hline Não agrícola $(c)$ & 563 & 546 & 568 & 559 & 585 & 655 & 666 & 678 & 718 & $3,6^{* * *}$ \\
\hline Não remunerada $(e)$ & 1.258 & 125 & 190 & 116 & 182 & 104 & 471 & 1.050 & 751 & $10,5^{\mathrm{NS}}$ \\
\hline Autoconstrução ${ }^{3}(f)$ & 569 & 457 & 1.015 & 468 & 435 & 305 & 347 & 398 & 610 & $-4,4^{\mathrm{NS}}$ \\
\hline Ocupada restrita ${ }^{4}(g)$ & 562 & 548 & 568 & 560 & 586 & 657 & 667 & 677 & 718 & $3,6^{* * *}$ \\
\hline Agrícola $(d)$ & 484 & 451 & 456 & 469 & 470 & 491 & 562 & 559 & 572 & $3,0^{* * *}$ \\
\hline Não remunerada $(h)$ & 259 & 183 & 165 & 182 & 204 & 240 & 257 & 271 & 268 & $4,2^{*}$ \\
\hline Autoconsumo ${ }^{5}(i)$ & 324 & 299 & 287 & 293 & 309 & 336 & 373 & 365 & 392 & $3,4^{* * *}$ \\
\hline Ocupada restrita $^{4}(j)$ & 505 & 474 & 486 & 503 & 504 & 528 & 609 & 612 & 620 & $3,6^{* * *}$ \\
\hline Não ocupada² $(b)$ & 345 & 210 & 219 & 208 & 181 & 193 & 177 & 206 & 193 & $-4,7^{* *}$ \\
\hline Não economicamente ativa & 344 & 338 & 311 & 334 & 366 & 398 & 450 & 445 & 470 & $5,1^{* * *}$ \\
\hline
\end{tabular}

Notas:

1. Relativo à contagem da PEA atualmente em uso e corresponde a $a+b$. Exclui as áreas rurais dos estados do Acre, Amapá, Amazonas, Pará, Rondônia e Roraima.

2. Total de pessoas desocupadas que procuraram emprego no período de referência.

3. Total de pessoas ocupadas ao menos uma hora por semana na construção de estrada privativa, poço ou outra benfeitoria (exceto reforma) para seu uso, ou para uso de pelo menos um membro da unidade domiciliar.

4. Enumeração da PEA excluindo-se o pessoal ocupado ao menos uma hora por semana, no trabalho principal ou secundário, em atividades de autoconsumo ou autoconstrução e o pessoal ocupado sem remuneração em dinheiro, produto ou serviço e com carga horária semanal inferior a quinze horas. Abrange, grosso modo, o pessoal ocupado em atividade comercial ou a PEA restrita. Na população rural a PEA restrita equivale a $b+g+j$, pelo que a PEA rural ampliada equivale $\mathrm{a} b+c+d$ ou, mais apropriadamente, $\mathrm{a} b+e+f+g+h+i+j$.

5. Total de pessoas ocupadas ao menos uma hora por semana na agricultura, silvicultura, pecuária, extração vegetal ou piscicultura para sua alimentação, ou de pelo menos um membro da unidade domiciliar.

6. *** **, * significativo, respectivamente, a 5\%, $10 \%$ e $20 \%$ de probabilidade pelo teste $t$ de Student; ${ }^{\text {NS }}$ não significativo a $20 \%$ de probabilidade pelo teste $t$ de Student.

7. Valores atualizados com base no INPC de setembro de 2009.

Fonte: Pesquisa Nacional por Amostra de Domicílios (PNAD) de 2001 a 2009, do Instituto Brasileiro de Geografia e Estatística (IBGE) Elaboração: ASE / Iapar. 
Tabela 6. Evolução do índice de Gini da distribuição do rendimento mensal de todas as fontes da população brasileira, total e rural, e taxa média anual de crescimento (i) no período 2001-2009

\begin{tabular}{|c|c|c|c|c|c|c|c|c|c|c|}
\hline \multirow{2}{*}{ Item } & \multicolumn{9}{|c|}{ Índice de Gini } & \multirow{2}{*}{$\begin{array}{l}i^{2} \\
\%\end{array}$} \\
\hline & 2001 & 2002 & 2003 & 2004 & 2005 & 2006 & 2007 & 2008 & 2009 & \\
\hline Brasil & 0,572 & 0,573 & 0,566 & 0,559 & 0,552 & 0,548 & 0,535 & 0,531 & 0,521 & $-1,2^{* * *}$ \\
\hline Brasil rural ${ }^{1}$ & 0,491 & 0,486 & 0,511 & 0,500 & 0,483 & 0,482 & 0,479 & 0,463 & 0,460 & $-0,9 * * *$ \\
\hline
\end{tabular}

Notas:

1. Afora as áreas rurais dos estados do Acre, Amapá, Amazonas, Pará, Rondônia e Roraima.

2 . ${ }^{* * *}$ significativo a $5 \%$ de probabilidade pelo teste $t$ de Student.

Fonte: Fonte: Pesquisa Nacional por Amostra de Domicílios (PNAD) de 2001 a 2009, do Instituto Brasileiro de Geografia e Estatística (IBGE). Elaboração: ASE / Iapar.

Quanto à distribuição do rendimento familiar per capita, em conformidade com as faixas de $\mathrm{SM}$ e relativas ao conjunto das pessoas da família extensa, percebe-se uma diminuição relativa da população em situação de extrema pobreza (pessoas com rendimento mensal de até $1 / 4$ do $\mathrm{SM})$, ainda que não tenha ocorrido uma redução do total da população pobre (pessoas com rendimento de mais de $1 / 4$ até $1 / 2 \mathrm{SM})$, particularmente em função do acelerado crescimento $(3,9 \%$ ao ano) da população com rendimento de mais de $1 / 4$ até $1 / 2 \mathrm{SM}$ (Tabela 7).
A redução absoluta da população extremamente pobre levou à contração de sua participação relativa no conjunto das pessoas da família extensa e com rendimento familiar per capita, particularmente em função da estagnação numérica da população situada no estrato de mais de $1 / 4$ até $1 / 2$ SM. Ainda, a estagnação da participação relativa da população pobre também se deveu ao acelerado aumento no total de pessoas nas faixas de mais de $1 / 2$ até $1 \mathrm{SM}$ e de mais de 1 até $2 \mathrm{SM}$ e, em menor parte, à redução absoluta e relativa da população rica (com mais de $2 \mathrm{SM}$ ).

Tabela 7. Evolução da população e da participação relativa das pessoas da família extensa ${ }^{1}$ brasileira com rendimento familiar per capita, por faixa de salário mínimo (SM), e taxa média anual de crescimento (i) no período 2001-2009

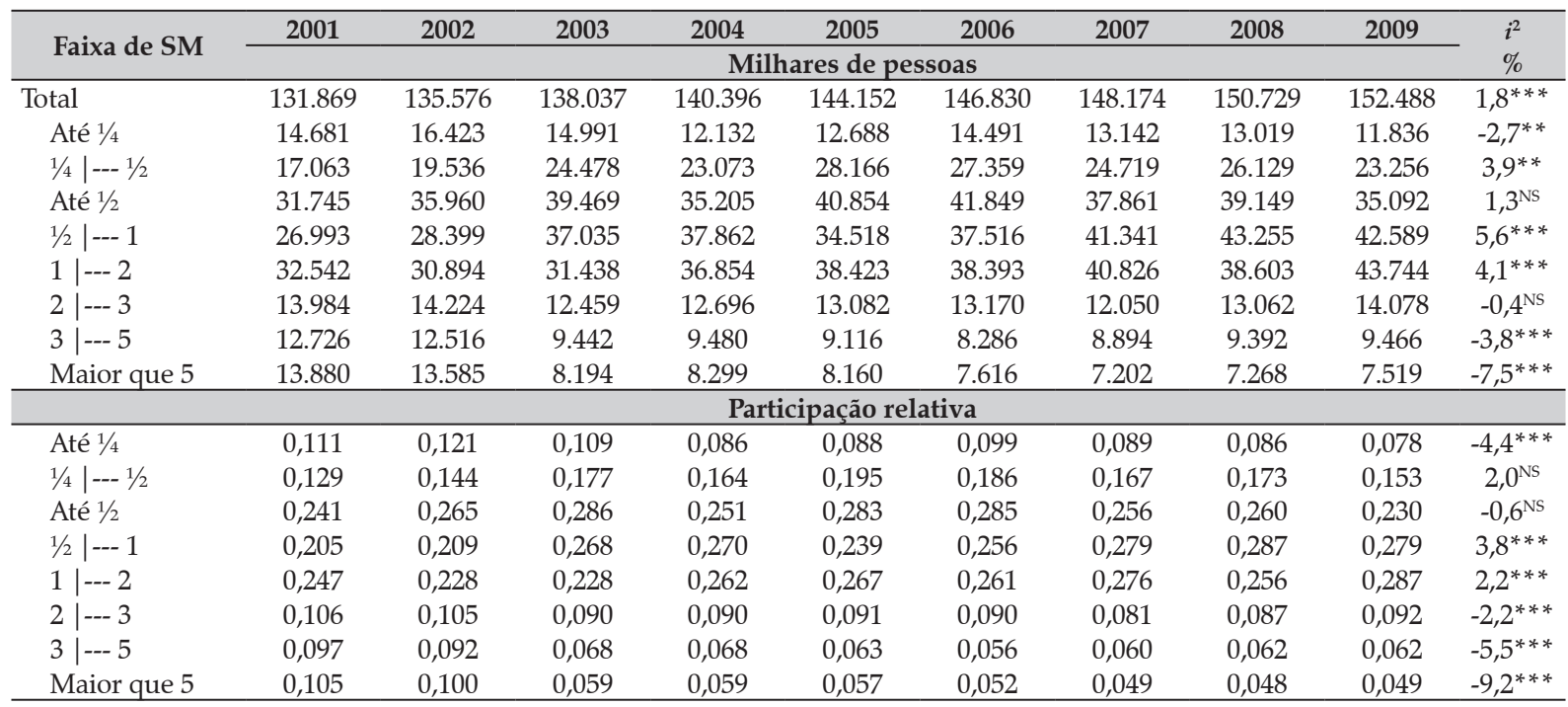

Notas:

1. Corresponde ao conjunto dos integrantes do núcleo familiar básico mais os agregados, conforme especificação utilizada na PNAD. Não considera as áreas rurais dos estados do Acre, Amapá, Amazonas, Pará, Rondônia e Roraima.

2. *** ${ }^{* *}$ significativo, respectivamente, a $5 \%$ e $10 \%$ de probabilidade pelo teste $t$ de Student; N não significativo a $20 \%$ de probabilidade pelo teste $t$ de Student.

Fonte: Pesquisa Nacional por Amostra de Domicílios (PNAD) de 2001 a 2009, do Instituto Brasileiro de Geografia e Estatística (IBGE).

Elaboração: ASE / Iapar. 
A redução absoluta da população extremamente pobre ocorreu em função da melhoria de renda no meio urbano, visto que, na área rural, a população pobre cresceu em termos absolutos (Tabela 8). Porém, isso não alterou a sua participação relativa, uma vez que houve crescimento da população do estrato de mais de $1 / 2$ até $1 \mathrm{SM}$, que é o estrato relativamente mais populoso, estabilidade da população com mais de 1 até 2 SM e acentuada redução absoluta e relativa da população com rendimento superior a $2 \mathrm{SM}$.

Considerando-se o rendimento do conjunto das pessoas da família extensa com rendimento familiar per capita, observa-se um panorama mais positivo, visto que o aumento anual foi consistente e acelerado na faixa das pessoas pobres, enquanto que o rendimento da população total, em termos absolutos, apresentou baixa taxa de crescimento no período (Tabela 9). Essa circuns- tância, juntamente com a não expansão do rendimento das populações situadas nos dois estratos superiores, conduziu à rápida elevação da participação relativa dos mais pobres no total do rendimento das pessoas da família extensa com rendimento per capita.

Com relação à evolução da participação relativa do rendimento familiar per capita, da família extensa com domicílio rural, observou-se acelerada elevação absoluta e relativa do rendimento da camada mais pobre da população, entre 2001 e 2009. Tal elevação foi decorrente do baixo incremento da renda total das pessoas da família extensa com rendimento familiar per capita, bem como do maior ritmo de expansão do rendimento da população de mais de $1 / 2$ até $1 \mathrm{SM}$ e de mais de 1 até $2 \mathrm{SM}$ e da redução no grupo das pessoas com rendimento superior a 2 SM (Tabela 10).

Tabela 8. Evolução da população e da participação relativa das pessoas da família extensa ${ }^{1}$ brasileira com rendimento familiar per capita e residente na área rural, por faixa de salário mínimo (SM), e taxa média anual de crescimento (i) no período 2001-2009

\begin{tabular}{|c|c|c|c|c|c|c|c|c|c|c|}
\hline \multirow{2}{*}{ Faixa de SM } & 2001 & 2002 & 2003 & 2004 & 2005 & 2006 & 2007 & 2008 & 2009 & $i^{2}$ \\
\hline & \multicolumn{9}{|c|}{ Milhares de pessoas } & $\%$ \\
\hline Total & 20.552 & 20.988 & 21.145 & 21.243 & 22.096 & 22.025 & 22.202 & 22.064 & 22.071 & $1,0^{* * *}$ \\
\hline Até $1 / 4$ & 3.785 & 3.922 & 5.434 & 4.726 & 5.141 & 5.642 & 5.141 & 5.082 & 4.484 & $2,6^{*}$ \\
\hline $1 / 4 \mid--1 / 2$ & 4.410 & 4.750 & 5.903 & 5.593 & 6.503 & 6.097 & 5.866 & 5.958 & 5.400 & $2,6^{*}$ \\
\hline Até $1 / 2$ & 8.195 & 8.672 & 11.337 & 10.318 & 11.643 & 11.739 & 11.006 & 11.040 & 9.884 & $2,6^{*}$ \\
\hline $1 / 2 \mid--1$ & 5.517 & 5.902 & 5.637 & 5.986 & 5.477 & 5.412 & 5.936 & 6.531 & 6.366 & $1,5^{* *}$ \\
\hline $1 \mid--2$ & 4.304 & 3.974 & 2.900 & 3.676 & 3.752 & 3.762 & 4.104 & 3.332 & 4.438 & $0,5^{\mathrm{NS}}$ \\
\hline $2 \mid--3$ & 1.234 & 1.232 & 703 & 705 & 681 & 672 & 619 & 675 & 828 & $-6,0^{* *}$ \\
\hline $3 \mid--5$ & 800 & 756 & 378 & 357 & 356 & 292 & 329 & 308 & 366 & $-10,0^{* * *}$ \\
\hline \multirow[t]{2}{*}{ Maior que 5} & 503 & 451 & 191 & 201 & 187 & 148 & 207 & 177 & 188 & $-10,8^{* * *}$ \\
\hline & \multicolumn{9}{|c|}{ Participação relativa } & \\
\hline Até $1 / 4$ & 0,184 & 0,187 & 0,257 & 0,222 & 0,233 & 0,256 & 0,232 & 0,230 & 0,203 & $1,6^{\mathrm{NS}}$ \\
\hline $1 / 4 \mid--1 / 2$ & 0,215 & 0,226 & 0,279 & 0,263 & 0,294 & 0,277 & 0,264 & 0,270 & 0,245 & $1,7^{\mathrm{NS}}$ \\
\hline Até $1 / 2$ & 0,399 & 0,413 & 0,536 & 0,486 & 0,527 & 0,533 & 0,496 & 0,500 & 0,448 & $1,6^{\mathrm{NS}}$ \\
\hline $1 / 2 \mid--1$ & 0,268 & 0,281 & 0,267 & 0,282 & 0,248 & 0,246 & 0,267 & 0,296 & 0,288 & $0,5^{\mathrm{NS}}$ \\
\hline $1 \mid--2$ & 0,209 & 0,189 & 0,137 & 0,173 & 0,170 & 0,171 & 0,185 & 0,151 & 0,201 & $-0,4^{\mathrm{NS}}$ \\
\hline $2 \mid--3$ & 0,060 & 0,059 & 0,033 & 0,033 & 0,031 & 0,031 & 0,028 & 0,031 & 0,038 & $-6,9^{* *}$ \\
\hline $3 \mid--5$ & 0,039 & 0,036 & 0,018 & 0,017 & 0,016 & 0,013 & 0,015 & 0,014 & 0,017 & $-10,8^{* * *}$ \\
\hline Maior que 5 & 0,024 & 0,021 & 0,009 & 0,009 & 0,008 & 0,007 & 0,009 & 0,008 & 0,009 & $-11,7^{* * *}$ \\
\hline
\end{tabular}

Notas:

1. Corresponde ao conjunto dos integrantes do núcleo familiar básico mais os agregados, conforme especificação utilizada na PNAD. Exclui as áreas rurais dos estados do Acre, Amapá, Amazonas, Pará, Rondônia e Roraima.

2 . *** ${ }^{* *},{ }^{*}$ significativo, respectivamente, a $5 \%, 10 \%$ e $20 \%$ de probabilidade pelo teste $t$ de Student; ${ }^{\text {NS }}$ não significativo a $20 \%$ de probabilidade pelo teste $t$ de Student.

Fonte: Pesquisa Nacional por Amostra de Domicílios (PNAD) de 2001 a 2009, do Instituto Brasileiro de Geografia e Estatística (IBGE). Elaboração: ASE / Iapar. 
Tabela 9. Evolução do rendimento e da participação relativa do rendimento das pessoas da família extensa ${ }^{1}$ brasileira com rendimento familiar per capita, por faixa de salário mínimo (SM), e taxa média anual de crescimento (i) no período 2001-2009

\begin{tabular}{|c|c|c|c|c|c|c|c|c|c|c|}
\hline \multirow{2}{*}{ Faixa de SM } & 2001 & 2002 & 2003 & 2004 & 2005 & 2006 & 2007 & 2008 & 2009 & $i^{2}$ \\
\hline & \multicolumn{9}{|c|}{ Milhões de R\$ } & $\%$ \\
\hline Total & 98.526 & 100.577 & 74.201 & 77.435 & 84.277 & 93.203 & 96.369 & 102.227 & 105.763 & $1,7^{\mathrm{NS}}$ \\
\hline Até $1 / 4$ & 670 & 809 & 790 & 623 & 712 & 950 & 856 & 921 & 798 & $2,8^{*}$ \\
\hline $1 / 4$ |-- $1 / 2$ & 1.900 & 2.389 & 3.041 & 2.779 & 3.908 & 4.323 & 3.816 & 4.396 & 3.770 & $9,5^{* * *}$ \\
\hline Até $1 / 2$ & 2.570 & 3.198 & 3.831 & 3.402 & 4.620 & 5.273 & 4.672 & 5.317 & 4.569 & $8,1^{* * *}$ \\
\hline $1 / 2 \mid--1$ & 5.980 & 6.842 & 8.975 & 8.883 & 9.043 & 11.168 & 12.485 & 14.211 & 13.444 & $11,1^{* * *}$ \\
\hline $1 \mid--2$ & 14.465 & 14.473 & 14.262 & 16.730 & 18.794 & 21.323 & 23.778 & 23.613 & 26.296 & $8,9^{* * *}$ \\
\hline $2 \mid--3$ & 10.635 & 11.216 & 9.647 & 10.141 & 11.250 & 13.065 & 12.431 & 13.698 & 14.830 & $4,6^{* * *}$ \\
\hline $3 \mid--5$ & 15.230 & 15.406 & 11.606 & 11.861 & 12.380 & 12.969 & 14.331 & 15.499 & 15.668 & $1,1^{\mathrm{NS}}$ \\
\hline \multirow[t]{2}{*}{ Maior que 5} & 49.646 & 49.443 & 25.880 & 26.419 & 28.191 & 29.404 & 28.672 & 29.890 & 30.957 & $-5,0^{*}$ \\
\hline & \multicolumn{9}{|c|}{ Participação relativa } & \\
\hline Até $1 / 4$ & 0,007 & 0,008 & 0,011 & 0,008 & 0,008 & 0,010 & 0,009 & 0,009 & 0,008 & $1,1^{\mathrm{NS}}$ \\
\hline $1 / 4 \mid--1 / 2$ & 0,019 & 0,024 & 0,041 & 0,036 & 0,046 & 0,046 & 0,040 & 0,043 & 0,036 & $7,7^{* *}$ \\
\hline Até $1 / 2$ & 0,026 & 0,032 & 0,052 & 0,044 & 0,055 & 0,057 & 0,048 & 0,052 & 0,043 & $6,2^{* *}$ \\
\hline $1 / 2 \mid--1$ & 0,061 & 0,068 & 0,121 & 0,115 & 0,107 & 0,120 & 0,130 & 0,139 & 0,127 & $9,2^{* * *}$ \\
\hline $1 \mid--2$ & 0,147 & 0,144 & 0,192 & 0,216 & 0,223 & 0,229 & 0,247 & 0,231 & 0,249 & $7,0^{* * *}$ \\
\hline $2 \mid--3$ & 0,108 & 0,112 & 0,130 & 0,131 & 0,133 & 0,140 & 0,129 & 0,134 & 0,140 & $2,8^{* * *}$ \\
\hline $3 \mid--5$ & 0,155 & 0,153 & 0,156 & 0,153 & 0,147 & 0,139 & 0,149 & 0,152 & 0,148 & $-0,7^{*}$ \\
\hline Maior que 5 & 0,504 & 0,492 & 0,349 & 0,341 & 0,335 & 0,315 & 0,298 & 0,292 & 0,293 & $-6,6^{* * *}$ \\
\hline
\end{tabular}

Notas:

1. Corresponde ao conjunto dos integrantes do núcleo familiar básico mais os agregados, conforme especificação utilizada na PNAD. Não considera as áreas rurais dos estados do Acre, Amapá, Amazonas, Pará, Rondônia e Roraima.

2. *** ${ }^{* *},{ }^{*}$ significativo, respectivamente, a $5 \%, 10 \%$ e $20 \%$ de probabilidade pelo teste $t$ de Student; ${ }^{\text {NS }}$ não significativo a $20 \%$ de probabilidade pelo teste $t$ de Student.

Fonte: Pesquisa Nacional por Amostra de Domicílios (PNAD) de 2001 a 2009, do Instituto Brasileiro de Geografia e Estatística (IBGE). Elaboração: ASE / Iapar.

Tabela 10. Evolução do rendimento e da participação relativa do rendimento da família extensa ${ }^{1}$ brasileira com rendimento familiar per capita e com domicílio rural, por faixa de salário mínimo (SM), e taxa média anual de crescimento (i) no período 2001-2009

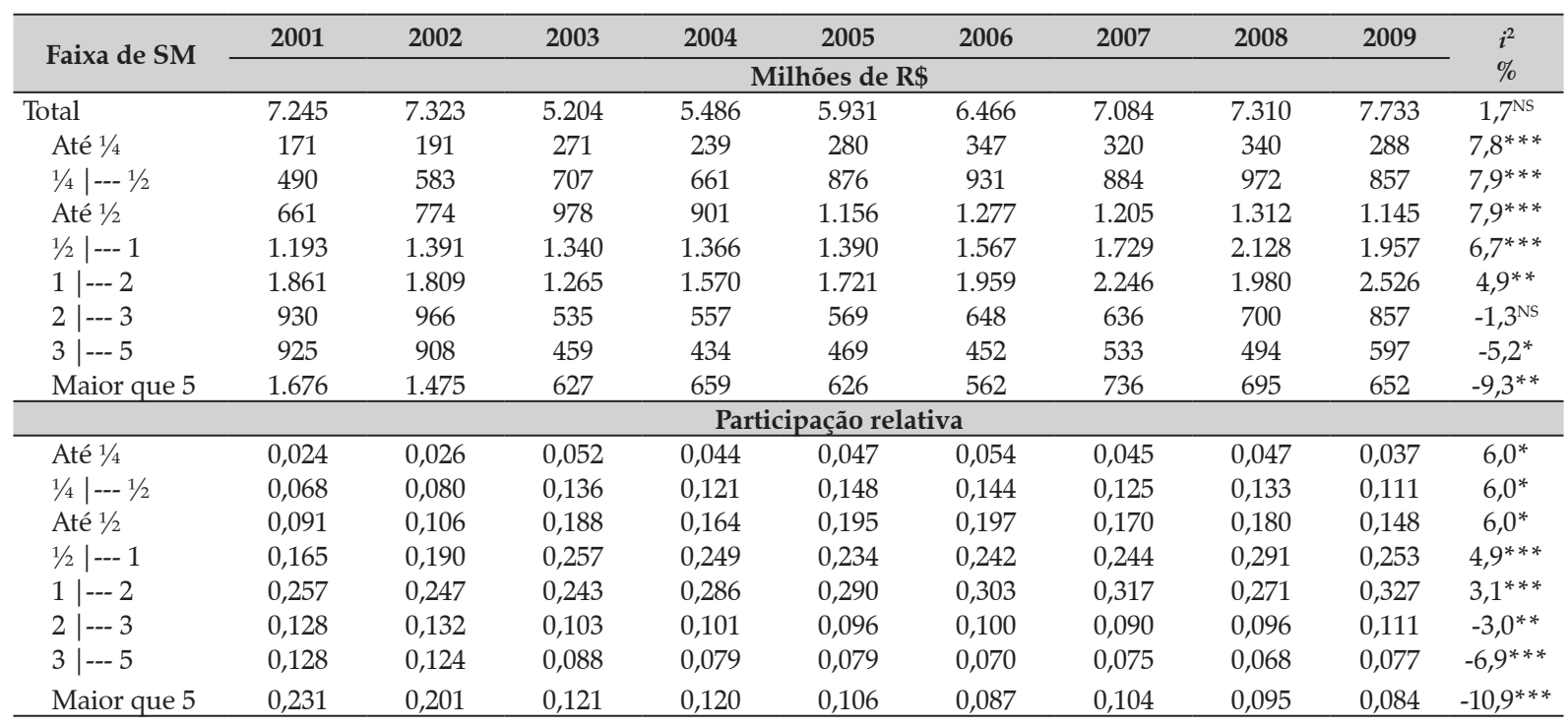

Notas:

1. Corresponde ao conjunto dos integrantes do núcleo familiar básico mais os agregados, conforme especificação utilizada na PNAD. Exclui as áreas rurais dos estados do Acre, Amapá, Amazonas, Pará, Rondônia e Roraima.

2. ***,**, * significativo, respectivamente, a $5 \%, 10 \%$ e $20 \%$ de probabilidade pelo teste $t$ de Student; ${ }^{\text {NS }}$ não significativo a $20 \%$ de probabilidade pelo teste $t$ de Student.

Fonte: Pesquisa Nacional por Amostra de Domicílios (PNAD) de 2001 a 2009, do Instituto Brasileiro de Geografia e Estatística (IBGE)

Elaboração: ASE / Iapar. 
O atual perfil do meio rural não se mostrou tão evidente quando considerada a evolução das pessoas da família extensa com rendimento familiar per capita, devido à estabilidade na desigualdade do acesso ao rendimento nas faixas de até $1 / 4 \mathrm{SM}$ e de mais de $1 / 4$ até $1 / 2 \mathrm{SM}$, mesmo com o expressivo acréscimo do rendimento médio dos agrupamentos populacionais dessas faixas de SM (Tabela 11). O mesmo ocorreu para o estrato agregado de até $1 / 2 \mathrm{SM}$, sinalizando, com isso, a ocorrência de um "arrefecimento" parcial da pobreza rural no período de 2001 a 2009. Em contrapartida se percebe que, embora tenha crescido o total das pessoas da família extensa com rendimento familiar per capita, na nova ruralidade se denota, em termos gerais, um empobrecimento relativo tanto em função do acentuado aumento na população pobre quanto da redução, também acentuada, no subgrupo das pessoas de maior poder aquisitivo.

Isso indica que, na zona rural, ao contrário do que se verificou no meio urbano, o crescimento no total de pessoas em situação de extrema

Tabela 11. Evolução do índice de Gini e do valor médio do rendimento das pessoas da família extensa ${ }^{1}$ brasileira, total e rural, com rendimento familiar per capita, por faixa de salário mínimo (SM), e taxa média anual de

crescimento (i) no período 2001-2009

\begin{tabular}{|c|c|c|c|c|c|c|c|c|c|c|}
\hline \multirow{2}{*}{ Faixa de SM } & 2001 & 2002 & 2003 & 2004 & 2005 & 2006 & 2007 & 2008 & 2009 & $i^{3}$ \\
\hline & \multicolumn{9}{|c|}{ Índice de Gini } & $\%$ \\
\hline Brasil & 0,620 & 0,619 & 0,569 & 0,559 & 0,556 & 0,551 & 0,542 & 0,534 & 0,529 & $-2,0^{* * *}$ \\
\hline Até $1 / 4$ & 0,221 & 0,227 & 0,227 & 0,225 & 0,222 & 0,231 & 0,232 & 0,228 & 0,233 & $0,5^{* *}$ \\
\hline $1 / 4 \mid--1 / 2$ & 0,114 & 0,116 & 0,113 & 0,112 & 0,122 & 0,114 & 0,112 & 0,113 & 0,109 & $-0,4^{\mathrm{NS}}$ \\
\hline Até $1 / 2$ & 0,274 & 0,277 & 0,247 & 0,236 & 0,238 & 0,242 & 0,238 & 0,235 & 0,236 & $-1,9 * * *$ \\
\hline Brasil rural & 0,567 & 0,548 & 0,520 & 0,505 & 0,497 & 0,494 & 0,500 & 0,487 & 0,479 & $-1,9 * * *$ \\
\hline Até $1 / 4$ & 0,235 & 0,239 & 0,241 & 0,225 & 0,227 & 0,244 & 0,245 & 0,238 & 0,246 & $0,5^{\mathrm{NS}}$ \\
\hline $1 / 4 \mid--1 / 2$ & 0,113 & 0,115 & 0,114 & 0,114 & 0,123 & 0,117 & 0,113 & 0,117 & 0,111 & $0,0^{\mathrm{NS}}$ \\
\hline Até $1 / 2$ & 0,117 & 0,116 & 0,123 & 0,118 & 0,106 & 0,106 & 0,116 & 0,122 & 0,113 & $-0,3^{\mathrm{NS}}$ \\
\hline $1 / 2 \mid--1$ & 0,277 & 0,279 & 0,277 & 0,265 & 0,276 & 0,285 & 0,276 & 0,276 & 0,275 & $-0,0^{\mathrm{NS}}$ \\
\hline $1 \mid---2$ & 0,130 & 0,122 & 0,109 & 0,120 & 0,116 & 0,118 & 0,122 & 0,115 & 0,111 & $-1,0^{*}$ \\
\hline $2 \mid--3$ & 0,064 & 0,067 & 0,070 & 0,072 & 0,066 & 0,071 & 0,066 & 0,064 & 0,065 & $-0,4^{\mathrm{NS}}$ \\
\hline $3 \mid--5$ & 0,083 & 0,086 & 0,091 & 0,085 & 0,083 & 0,085 & 0,081 & 0,084 & 0,082 & $-0,6^{\mathrm{NS}}$ \\
\hline \multirow[t]{2}{*}{ Maior que 5} & 0,353 & 0,342 & 0,341 & 0,318 & 0,276 & 0,277 & 0,260 & 0,276 & 0,250 & $-4,4^{* * *}$ \\
\hline & \multicolumn{9}{|c|}{ Rendimento médio $(\mathrm{R} \$)^{2}$} & \\
\hline Brasil & 747 & 742 & 538 & 552 & 585 & 635 & 650 & 678 & 694 & $-0,1^{\mathrm{NS}}$ \\
\hline Até $1 / 4$ & 46 & 49 & 53 & 51 & 56 & 66 & 65 & 71 & 67 & $5,7^{* * *}$ \\
\hline $1 / 4 \mid--1 / 2$ & 111 & 122 & 124 & 120 & 139 & 158 & 154 & 168 & 162 & $5,4^{* * *}$ \\
\hline Até $1 / 2$ & 81 & 89 & 97 & 97 & 113 & 126 & 123 & 136 & 130 & $6,7^{* * *}$ \\
\hline Brasil rural & 353 & 349 & 246 & 258 & 268 & 294 & 319 & 331 & 350 & $0,8^{\mathrm{NS}}$ \\
\hline Até $1 / 4$ & 45 & 49 & 50 & 51 & 54 & 61 & 62 & 67 & 64 & $5,1^{* * *}$ \\
\hline $1 / 4 \mid--1 / 2$ & 111 & 123 & 120 & 118 & 135 & 153 & 151 & 163 & 159 & $5,1^{* * *}$ \\
\hline Até $1 / 2$ & 81 & 89 & 86 & 87 & 99 & 109 & 109 & 119 & 116 & $5,1^{* * *}$ \\
\hline $1 / 2 \mid--1$ & 216 & 236 & 238 & 228 & 254 & 290 & 291 & 326 & 307 & $5,2^{* * *}$ \\
\hline 1 |--- 2 & 432 & 455 & 436 & 427 & 459 & 521 & 547 & 594 & 569 & $4,3^{* * *}$ \\
\hline $2 \mid--3$ & 753 & 784 & 760 & 790 & 835 & 965 & 1.026 & 1.037 & 1.035 & $5,0^{* * *}$ \\
\hline $3 \mid--5$ & 1.157 & 1.201 & 1.215 & 1.216 & 1.317 & 1.550 & 1.618 & 1.603 & 1.632 & $5,2^{* * *}$ \\
\hline Maior que 5 & 3.331 & 3.269 & 3.288 & 3.279 & 3.355 & 3.793 & 3.560 & 3.922 & 3.467 & $1,7^{* *}$ \\
\hline
\end{tabular}

Notas:

1. Corresponde ao conjunto dos integrantes do núcleo familiar básico mais a pessoa agregada, conforme especificação utilizada na PNAD. Não considera as áreas rurais dos estados do Acre, Amapá, Amazonas, Pará, Rondônia e Roraima.

2. Valores atualizados pelo INPC - IBGE de setembro de 2009.

$3 . * *, * *, *$ significativo, respectivamente, a $5 \%, 10 \%$ e $20 \%$ de probabilidade pelo teste $t$ de Student; ${ }^{\text {Ns }}$ não significativo a $20 \%$ de probabilidade pelo teste $t$ de Student.

Fonte: Pesquisa Nacional por Amostra de Domicílios (PNAD) de 2001 a 2009, do Instituto Brasileiro de Geografia e Estatística (IBGE).

Elaboração: ASE / Iapar. 
pobreza e da população pobre fez com que a participação relativa das pessoas da família extensa em situação de pobreza correspondesse, em 2009, praticamente à metade da população rural de 10 anos ou mais de idade.

Todavia, embora no final do período em foco houvesse mais pessoas pobres no meio rural, é preciso destacar que o aumento dessa população não foi associado a uma redução do rendimento dessa camada da população, uma vez que o rendimento total e o rendimento médio foram crescentes. Reforça isso o fato de que o rendimento dessa população no ano inicial, 2001, correspondia a apenas $58 \%$ do rendimento apropriado no ano final da série, 2009.

Em súmula, no que se refere à variação do rendimento médio, da desigualdade na distribuição do rendimento e da população rural em situação de pobreza, entre 2001 e 2009, observou-se que os contornos do atual espaço rural brasileiro se mostram mais nítidos no âmbito do rendimento do que no contexto da ocupação das pessoas com 10 anos ou mais de idade. Contatou-se uma tendência de crescimento no total da população residente no meio rural - embora a uma taxa de $1 \%$ ao ano -, de gradativa criação e diversificação de postos de ocupação e de aumento do rendimento das pessoas. Essas tendências foram acompanhadas da redução da desigualdade econômica no conjunto das pessoas com rendimento familiar per capita. Verificou-se ainda que, embora tenha ocorrido um aumento absoluto da população em situação de pobreza, o rendimento desta população no período de 2001 a 2009 cresceu em ritmo mais acelerado, resultando no aumento do rendimento médio desta população.

\section{Considerações finais}

Os resultados obtidos remetem à aceitação das hipóteses de que, entre 2001 e 2009, no Brasil, houve uma continuidade do crescimento do tamanho e do rendimento da população rural de 10 anos ou mais de idade e uma diminuição da importância relativa da agropecuária como fonte de postos de ocupação.
Em comum à inusitada demografia da última década do século passado, tem-se que a atual ruralidade também é demarcada pela continuidade da expansão da PEA rural ocupada em atividade comercial não agrícola e pela retração da PEA ocupada na agricultura mercantil. De maneira similar, o novo cenário da ruralidade brasileira tem se caracterizado pela estabilidade na magnitude de sua população, não obstante o declínio na quantidade do pessoal ocupado na agricultura mercantil e tampouco o expressivo incremento do pessoal ocupado na produção para o próprio consumo.

O perfil do meio rural vem se apresentando de maneira mais acentuada no contexto da população rural com rendimento (de todas as fontes), comparativamente àquele do plano ocupacional. Seu contorno se manifesta de modo mais nítido no âmbito da PEA rural com rendimento e ocupada em atividade mercantil ou da PEA restrita rural ocupada. Além disso, destacaram-se as tendências de aumento absoluto e relativo do rendimento da população rural com 10 anos ou mais de idade, da PEA rural ocupada em atividade não agrícola e da PEA rural ocupada na produção de autoconsumo, bem como as tendências de crescimento absoluto e decréscimo relativo do rendimento da PEA rural ocupada na agricultura mercantil.

O atual cenário da área rural do Brasil também se diferenciou por ter apresentado, no período 2001-2009, taxas anuais de acréscimo do rendimento e do poder aquisitivo superiores ao da população urbana, numa conjuntura de redução da população em situação de extrema pobreza.

Assim, não obstante a continuidade da queda da participação relativa da população rural no conjunto da população residente no Brasil, a averiguação acerca das atuais tendências de variação de subgrupos da população rural no presente estudo permite indicar a relevância de uma revisão das estratégias de desenvolvimento rural. Uma vez que os resultados obtidos reforçam a pertinência do "novo rural" enquanto abordagem que permite captar de modo mais adequado o atual espaço rural brasileiro e que, por conse- 
guinte, pode melhor orientar o desenho de ações de desenvolvimento rural, visto que a renda auferida pela pessoa residente no meio rural é, cada vez mais, oriunda de atividades não agrícolas. Isto suscita um elenco mais eclético de ações do que as do âmbito das atividades agropecuárias - stricto sensu -, para a melhoria das condições de vida e de desenvolvimento rural.

No entanto, para se estabelecer essas ações de forma mais pontual é conveniente realizar averiguações ainda mais compartimentalizadas sobre a continuidade da redução da PEA rural ocupada na agricultura mercantil. Para tanto, se faz necessário delinear a distribuição e a intensidade desse decréscimo segundo, por exemplo, o tipo de ocupação, as principais atividades agropecuárias e o tamanho do empreendimento. Estas informações podem efetivamente contribuir para um delineamento mais preciso da agenda de pesquisa e desenvolvimento $(\mathrm{P} \& \mathrm{D})$ associado à agropecuária brasileira.

Além disso, as constatações desse estudo remetem a novas questões que deverão compor à agenda de políticas públicas voltadas ao desenvolvimento rural sustentável, ou seja: como diversificar a pauta de atividades para além da agricultura que gerem ocupação e renda para a população rural? Como diversificar as atividades agrícolas diante da tendência de contínuo decréscimo da PEA rural ocupada na agricultura mercantil? Como incentivar a expansão da produção para o próprio consumo no sentido de melhorias na segurança alimentar e nutricional?

\section{Referências}

ALVES, C. L. B. e PAULO, E. M. Mercado de trabalho rural cearense: evolução recente a partir dos dados da PNAD. Revista da ABET, São Paulo, SP, v. 11, n. 2, p. 47-61, 2012.

BALSADI, O. V. O novo rural paulista: evolução e perspectivas. Estudos Sociedade e Agricultura, Rio de Janeiro, RJ, n. 17, p. 81-103, 2001.

. Comportamento das ocupaçõesna agropecuária brasileira no período 1999-2003. Informações Econômicas, São Paulo, SP, v. 35, n. 9, 2005.
. Ocupações não agrícolas da população rural no Centro-Oeste brasileiro no período 2001-2005. Informações Econômicas, São Paulo, SP, v. 38, n. 11, p. 39-47, 2008.

. e BORIN, M. R. Ocupações agrícolas e nãoagrícolas no rural paulista: análise das evoluções no período 1990-2002. São Paulo em Perspectiva, São Paulo, SP, v. 20, n. 4, p. 155-174, 2006.

. e GOMES, E. G. Evolução das condições de vida das famílias de empregados na agricultura brasileira no período 1992-2004. Revista de Economia Agrícola, São Paulo, SP, v. 54, n. 2, 2007.

BASOTTI, A., NAZARENO, L. R. de e CINTRA, A.P. de U. Um ensaio sobre as famílias agrícolas paranaenses a partir das PNADs 1992, 1998, 2005 e 2007. Revista Paranaense de Desenvolvimento, Curitiba, PR, n. 117, p. 123-145, 2009.

CAMPANHOLA, C. e GRAZIANO DA SILVA, J. (Eds.). O novo rural: uma análise nacional e regional. Jaguariúna, SP: EMBRAPA, 2000a. Volume 1.

. e GRAZIANO DA SILVA, J. (Eds.). O novo rural: uma análise estadual: Nordeste. Jaguariúna, SP: EMBRAPA, 2000b. Volume 2.

. e GRAZIANO DA SILVA, J. (Eds.). O novo rural: uma análise estadual: Sul, Sudeste e Centro-Oeste. Jaguariúna, SP: EMBRAPA Meio Ambiente, 2000c. Volume 3.

. e GRAZIANO DA SILVA, J. (Eds.). O novo rural: políticas públicas. Jaguariúna, SP: EMBRAPA Meio Ambiente, 2000d. Volume 4.

. e GRAZIANO DA SILVA, J. (Eds.). O novo rural brasileiro: rendas das famílias rurais. Brasília, DF: EMBRAPA Informação Tecnológica, 2004a. Volume 5.

. e GRAZIANO DA SILVA, J. (Eds.). O novo rural brasileiro: novas atividades rurais. Brasília, DF: EMBRAPA Informação Tecnológica, 2004b. Volume 6.

. e GRAZIANO DA SILVA, J. (Eds.). O novo rural brasileiro: novas ruralidades e urbanização. Brasília, DF: EMBRAPA Informação Tecnológica, 2004c. Volume 7.

., SILVEIRA, F. G. e MAGALHÃES, L. C. G. de. O mercado do trabalho rural: evolução recente, composição da renda e dimensão regional. Rio de Janeiro: IPEA, 2009. (Texto para Discussão, 1398)

CUNHA, M. S. da. Transformações recentes no mercado de trabalho paranaense. Revista Paranaense de Desenvolvimento, Curitiba, PR, n. 115, p. 79-100, 2008.

DEL GROSSI, M. e GRAZIANO DA SILVA, J. Mudanças recentes no mercado de trabalho rural. Parcerias Estratégicas, Brasília, DF, v. 11, n. 22, p. 201-2016, 2006. 
FERREIRA, B., BALSADI, O. V., FREITAS, R. E. e ALMEIDA, A. N. de. Ocupações agrícolas e nãoagrícolas: trajetória e rendimentos no meio rural brasileiro. In: DE NEGRI, J. A., DE NEGRI, F. e COELHO, D. (Orgs.). Tecnologia, exportação e emprego. Brasília: IPEA, 2006. p. 445-488.

GRAZIANO DA SILVA, J. O novo rural brasileiro. Nova Economia, Belo Horizonte, MG, v. 7, n. 1, p. 43-81, 1997.

. Velhos e novos mitos do rural brasileiro. Estudos Avançados, São Paulo, SP, v. 15, n. 43, p. 37-50, 2001.

O novo rural brasileiro. 2. ed. Campinas, SP: UNICAMP, IE, 2002. (Coleção Pesquisas, 1)

.et al. O rural paulista: muito além do agrícola e do agrário. São Paulo em Perspectiva, São Paulo, SP, v. 10, n. 2, p. 60-72, 1996.

e DEL GROSSI, M. E. Rural nonfarm employment and incomes in Brazil: patterns and evolution. World Development, v. 29, n. 3, p. 443-453, 2001.

, DEL GROSSI, M. E. e CAMPANHOLA, C. O que há de realmente novo no rural brasileiro. Cadernos de Ciência e Tecnologia, Brasília, v. 19, n. 1, p. 37-67, 2002.

HOFFMANN, R. A distribuição da renda no Brasil no período 1992-2001. Economia e Sociedade, Campinas, v. 11, n. 2, p. 213-235, 2002.

. Estatística para economistas. 4. ed. São Paulo: Cengage Learning, 2006.

KAGEYAMA, A. Diversificação das rendas nos domicílios agrícolas no Brasil, 1992 a 2001. Economia e Sociedade, Campinas, SP, v. 12, n. 1, 2003.
KAGEYAMA, A. Mudanças no trabalho rural no Brasil, 1992-2002. Agricultura em São Paulo, São Paulo, SP, v. 51, n. 2, p. 71-84, 2004.

LAURENTI, A. C. A evolução do rendimento das pessoas na nova ruralidade brasileira. In: Congresso da Sociedade Brasileira de Economia, Administração e Sociologia Rural, 48., 2010, Campo Grande. Anais... Campo Grande: SOBER, 2010.

. Evolução da ocupação e do rendimento das pessoas no meio rural do Paraná no período 2001-2009. Revista Paranaense de Desenvolvimento, Curitiba, PR, v. 34, n. 124, p. 175-199, 2013.

. e DEL GROSSI, M.E. Evolução das pessoas ocupadas nas atividades agrícolas e não-agrícolas nas áreas rurais do Brasil. In: CAMPANHOLA, C. e GRAZIANO DA SILVA, J. (Eds.). O novo rural brasileiro: uma análise nacional e regional. Jaguariúna: EMBRAPA, 2000. Volume 1. p. 15-65.

. e DEL GROSSI, M. E. A nova ruralidade brasileira e os desafios para o reajuste da P\&D para a agropecuária. In: Congresso da Sociedade Brasileira de Economia, Administração e Sociologia Rural, 46., 2008, Rio Branco. Anais... Acre: SOBER, 2008.

NEY, M. G. e HOFFMANN, R. A contribuição das atividades agrícolas e não-agrícolas para a desigualdade de renda no Brasil rural. Economia Aplicada, v. 12, n. 3, p. 365-393, 2008.

SCHNEIDER, S. e NAVARRO, Z. As mudanças nas ocupações agrícola e não-agrícola na agricultura gaúcha: uma análise a partir dos dados das PNADs de 1981-97. Indicadores Econômicos FEE, Porto Alegre, v. 27, n. 4, p. 170-189, 2000. 
